Proceedings of the All-Polish Seminar on Mössbauer Spectroscopy, Goniądz, Poland, June 17-20, 2018

\title{
Materials Formed between Tin(II) Fluoride and Alkaline Earth Metal Fluorides and Chlorides
}

\author{
G. DÉnès ${ }^{a, *}$, A. Muntasar ${ }^{a}$, M.C. MAdamba ${ }^{a}$, H. Merazig ${ }^{b}$ And Z. Zhu ${ }^{a}$ \\ ${ }^{a}$ Laboratory of Solid State Chemistry and Mössbauer spectroscopy, Department of Chemistry and Biochemistry, \\ Concordia University, 7141 Sherbrooke St. West, Montreal, H4B 1R6, Qc, Canada \\ ${ }^{b}$ Unité de Recherche de Chimie de l'Environnement et Moléculaire Structurale CHEMS, \\ Université des frères Mentouri de Constantine, Constantine, Algeria
}

\begin{abstract}
This report deals with compounds of tin(II) fluoride, also commonly called stannous fluoride, $\mathrm{SnF}_{2}$, the structure of which is related to the fluorite $\left(\mathrm{CaF}_{2}\right)$ type. The fluorides are exceptionally high performance fluorideion conductors, particularly when $\mathrm{SnF}_{2}$ is combined with $\mathrm{PbF}_{2}$. This has been attributed to $\mathrm{Pb}^{2+}$ having a $6 s^{2}$ lone pair, making the ion softer than alkaline earth metal ions. The phases can be either ordered or disordered, or with gradual change from fully disordered to fully ordered. Some of the disordered phases are nanocrystalline. In $\mathrm{MSnF}_{4}(\mathrm{M}=\mathrm{Pb}$ and $\mathrm{Ba})$, a change from crystalline to nanocrystalline, simultaneous with the formation of two types of disorder, a positional disorder and an orientational disorder, is observed to take place upon an unusually short ball-milling time. One of the $\mathrm{SnF}_{2} / \mathrm{PbF}_{2}$ phases, $\mathrm{PbSn}_{4} \mathrm{~F}_{10}$, deserves a special attention: with full $\mathrm{Pb} / \mathrm{Sn}$ disorder and the undistorted fluorite-type $\beta-\mathrm{PbF}_{2}$ structure, just its existence seems to be a miracle, and as a consequence it is metastable with a fairly short life time. Tin(II) alkaline earth metal chloride fluorides were obtained only with barium, and one has a disordered form of the $\mathrm{BaClF}$ structure, that is itself derived from the fluorite-type structure of $\mathrm{BaF}_{2}$ by $\mathrm{Cl} / \mathrm{F}$ ordering in the form of alternating planar sheets of fluoride ions and corrugated sheets of chloride ions perpendicularly to the $c$ axis of the tetragonal unit-cell. The $\mathrm{Ba} / \mathrm{Sn}(\mathrm{II}) / \mathrm{Cl} / \mathrm{F}$ phase, doubly disordered $\mathrm{Ba}_{1-x} \mathrm{Sn}_{x} \mathrm{Cl}_{1+y} \mathrm{~F}_{1-y}$ solid solution was obtained, that has the BaClF structure, with two types of unique disorders: (i) a limited disorder between $\mathrm{Cl}$ and $\mathrm{F}$, the limits of the solid solution being a function of the method of preparation (precipitation or solid state reactions), (ii) a very unique disorder between $\mathrm{Ba}^{2+}$ ions, $\mathrm{Sn}^{2+}$ ions and $\mathrm{Sn}(\mathrm{II})$ covalently bonded on the same site. Disorder between the two types of bonding of divalent tin on the same site had never been observed before and is in direct violation with the normal criteria for substitution. In addition, the presence of $\mathrm{Sn}^{2+}$ on the much larger $\mathrm{Ba}^{2+}$ site results in $\mathrm{Sn}^{2+}$ being very much loose in the much oversized site, resulting in considerable rattling, that is frozen at cryogenic temperatures. Furthermore, the $\mathrm{Ba}_{1-x} \mathrm{Sn}_{x} \mathrm{Cl}_{1+y} \mathrm{~F}_{1-y}$ solid solution obtained by precipitation undergoes a disorder-disorder phase transition on heating, i.e. from one form of disorder to another. The study of these phases and their properties was made possible by a combined use of X-ray powder diffraction and ${ }^{119}$ Sn Mössbauer spectroscopy.
\end{abstract}

DOI: $10.12693 /$ APhysPolA.134.1021

PACS/topics: 82.80.Ej, 76.80.+y, 61.05.Qr, 61.66.Fn

\section{Introduction}

The crystal structure of alkali metals fluorides is dependent on the $r^{+} / r^{-}$ratio of the radius of the cation over that of the anion [1]. For $r^{+} / r^{-} \leq 0.414$ the metal ion coordination is tetrahedral $\left(\mathrm{BeF}_{2}, \mathrm{SiO}_{2}\right.$ type $)$, for $0.414<$ $r^{+} / r^{-} \leq 0.732$, it is distorted octahedral $\left(\mathrm{MgF}_{2}\right.$, rutile type), and for $r^{+} / r^{-}>0.732$, it is cubic, fluorite-type structure $\left(\mathrm{CaF}_{2}, \mathrm{SrF}_{2}\right.$ and $\left.\mathrm{BaF}_{2}\right)$ [1]. For $\beta-\mathrm{PbF}_{2}$ (cubic) the structure is also the fluorite-type, while $\alpha-\mathrm{PbF}_{2}$ has the orthorhombic structure of $\mathrm{PbCl}_{2}[1,2]$. The crystal structure of $\mathrm{BaCl}_{2}$ is also fluorite-type [1]. While the fluorite-type structure and $\mathrm{BaCl}_{2}$ are typically ionic, the structures of the three phases of $\mathrm{SnF}_{2}$ are covalent. Monoclinic $\alpha-\mathrm{SnF}_{2}$ has a molecular structure; it is made of $\mathrm{Sn}_{4} \mathrm{~F}_{8}$ tetramers with strong intermolecular interactions and it contains two kinds of tin atoms structurally different: $\mathrm{Sn}(1)$ is in a highly distorted $\mathrm{SnF}_{3} \mathrm{E}(\mathrm{E}=$ lone pair $)$

*corresponding author; e-mail: georges.denes@concordia.ca trigonal pyramidal coordination with a tetrahedral electron pair geometry, while $\operatorname{Sn}(2)$ is in a highly distorted $\mathrm{SnF}_{5} \mathrm{E}(\mathrm{E}=$ lone pair) square pyramidal coordination with an octahedral electron pair geometry $[3,4]$. The tetragonal high temperature phase $\gamma-\mathrm{SnF}_{2}$ has the structure of $\mathrm{TeO}_{2}$ with a seesaw $\mathrm{SnF}_{4} \mathrm{E}$ coordination, with a trigonal bipyramidal electron pair geometry, which is, in contrast with other similar coordinations, a distortion of a square antiprism $[5,6]$. On cooling, a second order displacive $\gamma \leftrightarrows \beta$ transition takes place to give ferroelastic $\beta-\mathrm{SnF}_{2}$. In $\beta-\mathrm{SnF}_{2}$, the coordination of tin is intermediate between a $\mathrm{SnF}_{4} \mathrm{E}$ seesaw and a $\mathrm{SnF}_{5} \mathrm{E}$ square pyramidal $[5,6]$. The tin valence orbitals are hybridized in all phases of $\mathrm{SnF}_{2}$ and bonding is covalent. Tin(II) has not been found to form ionic bonding with fluorine, however with chlorine, it can form either covalent bonding, for example in $\mathrm{SnCl}_{2} \cdot 2 \mathrm{H}_{2} \mathrm{O}$ [7] or ionic bonding, like in anhydrous $\mathrm{Ba}_{2} \mathrm{SnCl}_{6}$ [8]. In the chloride fluorides, such as SnClF [9] and $\mathrm{Sn}_{2} \mathrm{ClF}_{3}$ [10], tin(II) makes covalent bonds either with fluorine only to form cations that make ionic bonds with chloride ions, or with both fluorine and chlorine to form a polymeric covalent structure. 
The purpose of this work was to prepare new phases that would be hybrids of ionically bonded barium fluoride or chloride, or of lead(II) fluoride, and covalently bonded tin(II) fluoride, and see how the two modes of bonding would accommodate each other to create new materials. Only the phases, the structures of which are related to the fluorite-type, are described in details here. The structure and bonding of the compounds formed were studied by elemental analysis, X-ray powder diffraction and ${ }^{119} \mathrm{Sn}$ Mössbauer spectroscopy.

\section{Experimental}

\subsection{Materials preparation}

\subsubsection{Starting materials}

The following reactants were used for the syntheses: $\mathrm{SnF}_{2}$ 99\% from Ozark Mahoning, $\alpha-\mathrm{PbF}_{2} 99.9 \%$ from Alfa, $\mathrm{BaCl}_{2} \cdot 2 \mathrm{H}_{2} \mathrm{O}$ analytical grade from American Chemicals, $\mathrm{BaF}_{2}$ 99\% from Allied Chemicals and Dye Corporations, $\mathrm{Ca}\left(\mathrm{NO}_{3}\right)_{2} \cdot 4 \mathrm{H}_{2} \mathrm{O} \geq 99.0 \%$ from SigmaAldrich, $\mathrm{HF} 40 \%$ aqueous solution from Mallinckrodt, and doubly distilled or deionized water. Anhydrous $\mathrm{BaCl}_{2}$ was prepared by dehydrating the dihydrated salt. All crystalline reactants were checked by X-ray powder diffraction and were found to have only the expected peaks. In addition, $\mathrm{SnF}_{2}$ was checked by DTA and identified by the $\alpha \rightarrow \gamma$ transition at $150^{\circ} \mathrm{C}-160^{\circ} \mathrm{C}$ and melting point at $215^{\circ} \mathrm{C}$ [11]. The degree of hydration of $\mathrm{BaCl}_{2} \cdot 2 \mathrm{H}_{2} \mathrm{O}$ was checked by TGA and found to be 2.04 .

\subsubsection{Precipitation reactions}

For all precipitation reactions, the molar fraction $X_{A}$ ( $A=$ any reactant) was varied from 0.10 to 0.90 by increments of 0.10 for a coarse screening in order to identify reactions mixtures that result in new compounds being formed, and then a fine screening was performed in the regions of interest, as needed, by use of smaller increments. In all cases, the solution of one of the reactants was added dropwise to a solution of the other upon stirring. Aqueous solutions at ambient temperature were used in all cases. The precipitates were filtered, washed with a minimum amount of cold water and allowed to dry at ambient temperature.

\subsubsection{Reactions at high temperature in dry conditions}

The dehydration temperature of $\mathrm{BaCl}_{2} \cdot 2 \mathrm{H}_{2} \mathrm{O}$ was reported to be $113^{\circ} \mathrm{C}$ [12]. This was checked by thermogravimetric analysis (TGA), and it was found to be fully dehydrated at $140{ }^{\circ} \mathrm{C}$, and the mass loss was measured to be $14.71 \%$ (theoretical for $2 \mathrm{H}_{2} \mathrm{O}=14.75 \%$ ). To ensure that dry anhydrous $\mathrm{BaCl}_{2}$ was obtained, $\mathrm{BaCl}_{2} \cdot 2 \mathrm{H}_{2} \mathrm{O}$ was heated at $200^{\circ} \mathrm{C}$ for two hours in air, and then placed under vacuum while still hot to prevent rehydration.

Stoichiometric amounts of the dry reactants were intimately mixed by grinding in a mortar with a pestle. Then, the mixture was placed in a copper tube reactor that was pumped to remove air and filled with nitrogen in a glove box. Pumping and filling with nitrogen was done twice to ensure that residual air is reduced to a minimum. Temporary sealing of the copper tube reactors was carried out in the glove box, while final sealing was performed outside. The full details of the copper tube reactor method have already been described [13]. Then, the tubes were heated in an oven to the appropriate temperatures, and after the adequate heating time, they were taken out and quenched in air or in cold water, and then the tubes were opened according to the procedure described in Ref. [13].

Heating temperatures to obtain the phases of interest here were the following: $\mathrm{PbSn}_{4} \mathrm{~F}_{10}: 250^{\circ} \mathrm{C}, \alpha-\mathrm{PbSnF}_{4}$ : $250{ }^{\circ} \mathrm{C}, \beta-\mathrm{PbSnF}_{4}$ : $500^{\circ} \mathrm{C}$, the $\mathrm{Pb}_{1-x} \mathrm{Sn}_{x} \mathrm{~F}_{2}$ solid solution: $500^{\circ} \mathrm{C}, \mathrm{BaSnF}_{4}$ : $500^{\circ} \mathrm{C}$, the $\mathrm{Ba}_{1-x} \mathrm{Sn}_{x} \mathrm{Cl}_{1+y} \mathrm{~F}_{1-y}$ : $350^{\circ} \mathrm{C}$, the latter according to the following reaction scheme:

$$
\begin{aligned}
& \frac{1-2 x-y}{2} \mathrm{BaF}_{2}+x \mathrm{SnF}_{2}+\frac{1+y}{2} \mathrm{BaCl}_{2} \rightarrow \\
& \mathrm{Ba}_{1-x} \mathrm{Sn}_{x} \mathrm{Cl}_{1+y} \mathrm{~F}_{1-y} .
\end{aligned}
$$

\subsubsection{Phase transitions by ball-milling}

\section{and further treatments}

Some of the phases prepared by the above methods were subjected to ball-milling using a Wig L Bug ${ }^{\circledR}$ amalgamator from Crescent Dental MFG Co, with two steel balls. In some cases, the ball-milled phases were annealed under dry nitrogen in a copper tube reactor for two hours [13]. Others were stirred in water for $12 \mathrm{~h}$, then they were filtered, washed and allowed to dry according to the same procedures as for precipitates.

\subsection{Materials characterization}

\subsubsection{X-ray powder diffraction}

X-ray powder diffraction was carried out by use of a Philips PW1050 diffractometer that had been automated with the Sie112 Sietronics ${ }^{\circledR}$ system from Difftech. This allowed a phase identification of phases already known, by comparison with the diffraction patterns of starting materials and other possible side products already collected in our laboratory and by use of the $\mu$ PDSM Micro Powder Diffraction Search Match ${ }^{\circledR}$ from Fein-Marquat. Only the phases of interest in this study were subjected to further analysis.

\subsubsection{Mössbauer spectroscopy}

The Mössbauer spectra were recorded using the following setup. The source was a nominally $25 \mathrm{mCi}$ $\mathrm{Ca}^{119 m} \mathrm{SnO}_{3} \gamma$-ray source from Ritverc $\mathrm{GmbH}$. Isomer shits were referenced relative to a standard $\mathrm{CaSnO}_{3}$ absorber at ambient temperature. The counting system was a scintillation counter from Harshaw, equipped with a $1 \mathrm{~mm}$ thick (Tl)NaI crystal. A palladium foil was used to absorb the $25.04 \mathrm{keV}$ and the $25.72 \mathrm{keV}$ X-ray lines generated by the source decay from the metastable $11 / 2$ spin level of the ${ }^{119 m} \mathrm{Sn}$ precursor to the $3 / 2$ spin of the first excited state. The Doppler velocity $( \pm 10 \mathrm{~mm} / \mathrm{s})$ was generated by the use of an Elscint driving system, including a Mössbauer MVT-4 velocity transducer, a Mössbauer MDF-N-5 waveform generator, and a MFG-N-5 driver. The amplifier, the single channel analyzer, and 
the multichannel analyzer are combined in the Tracor Northern TN7200 system. After, the data were transferred to a computer for storage and processing. Low temperature spectra were recorded using an ADP Cryogenics helium closed-cycle refrigerator equipped with a two-stage Displex ${ }^{\circledR}$. Computer processing of the data was performed using the MOSGRAF-2009 suite [14].

\section{Theoretical considerations}

\subsection{Crystal structures and bonding type}

\subsubsection{Ionic bonding in the fluorite-type structure}

Figure 1 shows the relationship between the crystal structure of $\mathrm{BaF}_{2}$ and those of $\mathrm{BaClF}$ and $\mathrm{BaSnF}_{4}$. In unsubstituted $\mathrm{BaF}_{2}$ (Fig. 1b), the crystal system is cubic and the $\mathrm{Ba}^{2+}$ ions are in cubic $\left[\mathrm{MF}_{8}\right]$ coordination, however half of the cubes of fluorides ions do not contain any metal ions and are therefore vacant $\left[\square \mathrm{F}_{8}\right]$, where $\square$ is a metal ion vacancy. The coordination of the cation is cubic, while that of the anion is tetrahedral. The cubes of fluoride ions occupied by a metal ion and those nonoccupied alternate parallel to the axes of the unit-cell (Fig. 1b). The presence of a large number of empty sites at the metal ion vacancies has been held responsible for the significant fluoride ion conductivity of the fluoritetype structure, by a mechanism of the Frenkel defects using the metal ion vacancies for lodging fluoride ion interstitials, although that interpretation cannot explain why the conductivity of $\beta-\mathrm{PbF}_{2}$ is higher than that of $\mathrm{BaF}_{2}$ [15]. The structure of $\mathrm{BaClF}$ (Fig. 1a) is obtained from the structure of $\mathrm{BaF}_{2}$ (Fig. 1b) by ordering fluoride and chloride ions according to a $\mathrm{F}-\mathrm{Cl}$ sequence, parallel to the $c$ axis of the unit-cell. This results in a tetragonal distortion with a large increase of the $c$ unitcell parameter and a lattice change from face centered to primitive, however, there is no superstructure. These structures can be considered to be purely ionic since the $\mathrm{Ba}^{2+}$ ion has a noble gas configuration and is sufficiently large to have a negligible polarizing power, while the fluoride and chloride ions require much more highly polarizing cations to be polarized sufficiently to give bonding a significant amount of covalency, according to the Fajans rules $[16-18]$.

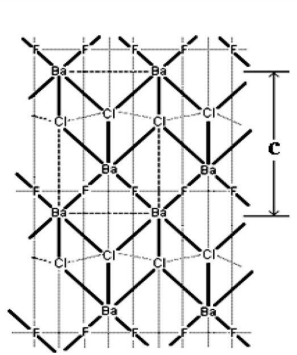

(a) BaCIF

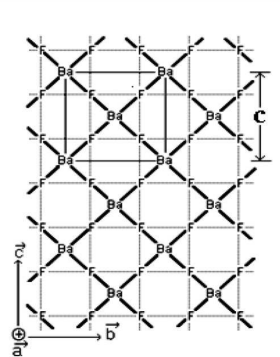

(b) $\mathrm{BaF}_{2}$

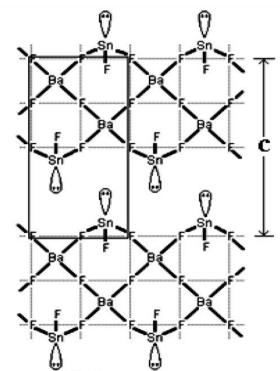

(c) $\mathrm{BaSnF}_{4}$
Fig. 1. Projection of the structures of (a) BaClF (F-Cl order), (b) non-substituted $\mathrm{BaF}_{2}$ and (c) $\mathrm{BaSnF}_{4}$ (Ba$\mathrm{Ba}-\mathrm{Sn}-\mathrm{Sn}$ order), all three in the system of axes of $\mathrm{BaF}_{2}$.

\subsubsection{The covalent structure of $\mathrm{SnF}_{2}$}

In contrast with the typically high melting point $(M p)$ of the fluorite-type $\mathrm{MF}_{2}\left(M p=1355^{\circ} \mathrm{C}\right.$ for $\mathrm{BaF}_{2}$ and $855^{\circ} \mathrm{C}$ for $\left.\mathrm{PbF}_{2}\right)$, the low melting point of $\mathrm{SnF}_{2}\left(215^{\circ} \mathrm{C}\right)$ suggests that its structure is molecular [11, 12]. The crystal structure of the phase of $\mathrm{SnF}_{2}$ stable at ambient conditions, $\alpha-\mathrm{SnF}_{2}$, confirms this: it is made of $\mathrm{Sn}_{4} \mathrm{~F}_{8}$ tetramers (Fig. 2) with covalent intramolecular $\mathrm{Sn}-\mathrm{F}$ bonds, while the intermolecular Sn...F interactions are much weaker, although quite stronger than normal $[3,4]$. The structure of the $\beta$ - and the $\gamma$-phases of $\mathrm{SnF}_{2}$ is a covalent network type, with clearly strongly covalent bonding $[5,6]$. The three phases of $\mathrm{SnF}_{2}$ have been shown to have a fluoride ion conductivity similar to that of $\beta$ $\mathrm{PbF}_{2}$ [19]. While the coordination of the metal ion in the fluorite-type is as high as allowed by the $r^{+} / r^{-}$ratio of the ionic radii, and it is not distorted, that of tin in all phases of $\mathrm{SnF}_{2}$ is reduced by one, two, or three, and its highly distorted (see Sect. 3.2.1 below).

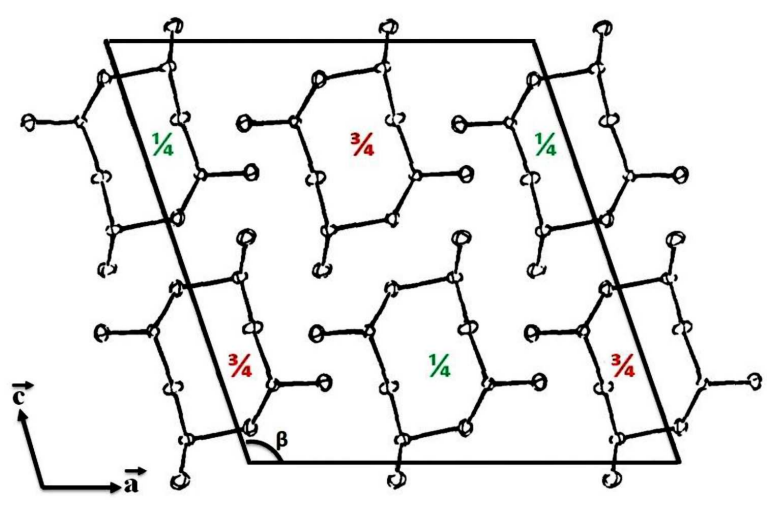

Fig. 2. The crystal structure of $\alpha-\mathrm{SnF}_{2}$ consists of $\mathrm{Sn}_{4} \mathrm{~F}_{8}$ tetramers. The $\mathrm{Sn}-\mathrm{F}$ bonds are covalent. The numbers $1 / 4$ and $3 / 4$ are the $z$ coordinate of the average height of each tetramer.

\section{2. $\operatorname{Tin}(I I)$ stereochemistry and Mössbauer spectroscopy}

\subsubsection{Tin(II) electronic structure and consequences} regarding bonding and coordination

Tin belongs to group 14 and period 5 of the periodic table and its electronic structure is $[\mathrm{Kr}] 4 d^{10} 5 s^{2} 5 p^{2}$. It has therefore four valences electrons and it can exist in the +4 full oxidation state (tetravalent) and in the +2 suboxidation state (divalent), both of which are stable at ambient conditions. In the latter case, only the two $5 p$ electrons are lost to form the $\mathrm{Sn}^{2+}$ ion or used to form covalent bonding, while the two $5 \mathrm{~s}$ electrons are unused and form a non-bonding electron pair, most commonly called a lone pair since, being unshared, it belongs to tin only. This can generate the following two bonding situations.

(a) The $\mathrm{Sn}^{2+}$ ion is formed. This situation is found mostly with large and weakly electronegative metalloids or non-metals, such as selenium, tellurium, and iodine, in rare cases chlorine, and in some cases bromine. In this 
situation, the $\mathrm{Sn}^{2+}$ electronic structure is $[\mathrm{Kr}] 4 d^{10} 5 s^{2}$, i.e. the tin lone pair remains on the native $5 s$ orbital. Bonding is ionic and the tin orbitals are not hybridized. Since $s$ orbitals are spherical, the lone pair being purely $5 s^{2}$ makes the stannous ion spherical, therefore its coordination can be highly symmetrical, like tetrahedral, octahedral, or cubic. Small distortions can occur, as allowed by local crystal symmetry. When the stannous ion is present, the lone pair is said to be "non-stereoactive", since being on an unhybridized spherical orbital, it does not modify the stereochemistry, i.e. it does not modify the tin coordination [20].

(b) Tin(II) is covalently bonded. This is found for small and highly electronegative non-metals, such as fluorine, oxygen, sulfur, and most of the time chlorine and bromine. In this bonding mode, the tin valence orbitals are hybridized. The following types of hybridization schemes have been observed, where the lone pair $E$ occupies one of the hybrid orbitals:

- $s p^{3}$ : tetrahedral electron pair geometry, trigonal pyramidal molecular geometry, $\mathrm{SnX}_{3} \mathrm{E}$, similar to the $\mathrm{NH}_{3}$ molecule;

- $s p^{3} d$ : trigonal bipyramidal electron pair geometry, seesaw molecular geometry, $\mathrm{SnX}_{4} \mathrm{E}$, similar to $\mathrm{SF}_{4}$;

- $s p^{3} d^{2}$ : octahedral electron pair geometry, square pyramidal molecular geometry, $\mathrm{SnX}_{5} \mathrm{E}$, similar to $\mathrm{ClF}_{5}$.

In all of the above cases, the geometry is in agreement with the expectations of the valence shell electron pair repulsion (VSEPR) model of Gillespie and Nyholm [21]. The VSEPR model accounts for the molecular geometry in nearly all cases for main group elements in free molecules. Deviations are observed sometimes in solids because of the contribution from the lattice energy. For example, in $\mathrm{SnO}$ and red $\mathrm{PbO}$, the coordination $\mathrm{MO}_{4} \mathrm{E}$ is square pyramidal, instead of seesaw expected by the VSEPR model $[22,23]$. Being located on a hybrid orbital, a stereoactive lone pair occupies a position in the valence shell of the tin atom that would otherwise be occupied by a bonding pair, connected to an atom in the tin sphere of coordination. Therefore, a stereoactive lone pair decreases the coordination number by at least one. In addition, in agreement with the VSEPR model, a lone pair occupies more room in the valence shell of an atom than a bonding pair, therefore lone pair-bonding pair repulsions are larger than the repulsion between two bonding pairs, and it results in an additional distortion of the polyhedron of coordination of covalently bonded tin, making the bond angles smaller. Two models have been used to analyze the decrease of coordination and distortions that result from the presence of a stereoactive lone pair. Both are based on electron pair repulsions such as described by the VSEPR model [21].

(a) The Galy-Andersson model is based on the fact that the stereoactive lone pair of the period 5 elements $\mathrm{In}(\mathrm{I}), \mathrm{Sn}(\mathrm{II}), \mathrm{Sb}(\mathrm{III}), \mathrm{Te}(\mathrm{IV}), \mathrm{I}(\mathrm{V})$, and $\mathrm{Xe}(\mathrm{VI})$, occupies a volume similar to that of an oxygen or a fluorine atom [20]. The coordination model thus obtained is tetrahedral for $\mathrm{SnX}_{3} \mathrm{E}$ (Fig. 3a), trigonal bipyramidal for $\mathrm{SnX}_{4} \mathrm{E}$ (Fig. 3b) and octahedral for $\mathrm{SnX}_{5} \mathrm{E}$ (Fig. 3c), where $\mathrm{X}$ is $\mathrm{F}$ or $\mathrm{O}$ and $\mathrm{E}$ is the lone pair, considered like if it were $\mathrm{F}$ or $\mathrm{O}$. These geometries are the same as what is commonly called the "electron pair geometry". In this model, the polyhedra are taken as being regular and the central atom is shifted away from the center of the polyhedron, toward the lone pair. This makes sense since the lone pair is unshared and is therefore closer to the central atom than the bonding pairs.

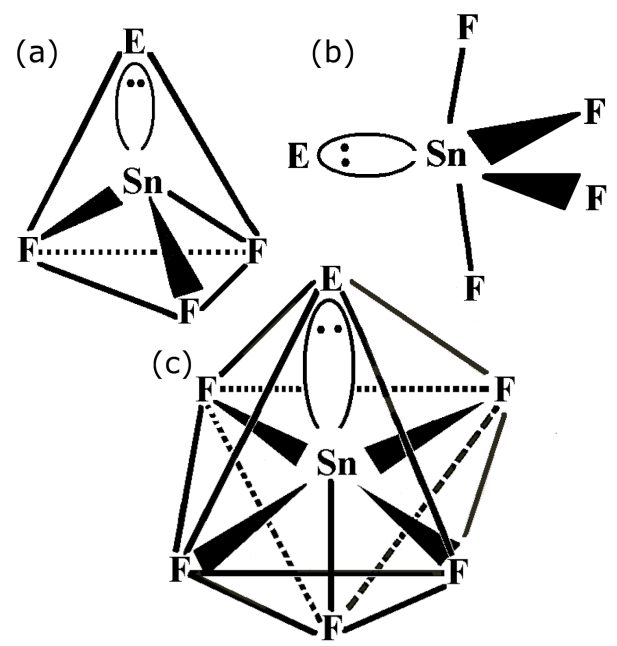

Fig. 3. Tin(II) polyhedra according to the GalyAndersson model: (a) $\mathrm{SnF}_{3} \mathrm{E}$, (b) $\mathrm{SnF}_{4} \mathrm{E}$, and (c) $\mathrm{SnF}_{5} \mathrm{E}$ $(\mathrm{E}=$ lone pair $)[20]$.
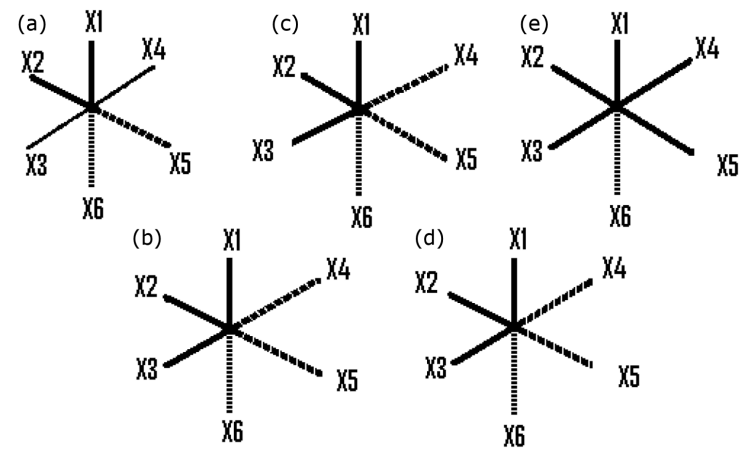

Fig. 4. Brown's models of distortion of a regular octahedron of fluorine or oxygen by a stereoactive lone pair found around $\mathrm{Sn}(\mathrm{II}), \mathrm{Sb}(\mathrm{III}), \mathrm{Te}(\mathrm{IV}), \mathrm{I}(\mathrm{V})$ and $\mathrm{Xe}(\mathrm{VI})[24]$.

(b) The Brown model is based on the fact that the $r_{+} / r_{-}$cation/anion ratio of ionic radii for the period 5 elements In(I), Sn(II), Sb(III), Te(IV), I(V), and Xe(VI) bonded to fluorine or oxygen is in the range to expect an octahedral coordination [24]. Brown's model examines how the stereoactive lone pair disturbs the coordination that would otherwise be octahedral, by (i) reducing the coordination number, since no bonding can take place in the direction of the lone pair, and (ii) by distorting the 
reduced coordination because the lone pair occupies more room in the valence shell of an atom than a bonding pair (2nd VSEPR rule) (Fig. 4) [24]. The following models are observed:

- $C$ model (Fig. 4c): three $\mathrm{X}$ ( $\mathrm{F}$ or $\mathrm{O}$ ) atoms are pushed away by the lone pair, to give a $\mathrm{SnX}_{3} \mathrm{X}_{3}^{\prime}$ coordination, which is actually a $\mathrm{SnX}_{3}$ trigonal pyramid (tetrahedral electron pair geometry taking the lone pair into consideration), the three $\mathrm{X}^{\prime}$ being pushed away so far that they form only very weak interactions with the central atom. The three $\mathrm{Sn}-\mathrm{X}$ interactions are strong covalent bonds, very significantly shorter than the sum of the ionic radii, indicating a substantial orbital overlap. In addition, the $\mathrm{X}-\mathrm{Sn}-\mathrm{X}$ angles are smaller than the $109.5^{\circ}$ expected for a tetrahedral electron pair geometry, due to intense lone pair-bonding pair repulsions. This is the same as the $\mathrm{SnX}_{3} \mathrm{E}$ tetrahedral model in GalyAndersson's model [20];

- A model (Fig. 4a): two X atoms are pushed away by the lone pair, to give a $\mathrm{SnX}_{4} \mathrm{X}_{2}^{\prime}$ coordination. With the two $\mathrm{X}^{\prime}$ pushed away by the lone pair, the real polyhedron is $\mathrm{SnX}_{4}$ with a seesaw shape (triangular bipyramidal electron pair geometry, including the lone pair). Distortions by the lone pair-bonding pair repulsions are of two types: (i) two kinds of bond lengths: the two equatorial Sn$\mathrm{X}_{\mathrm{eq}}$ bonds are shorter than the axial $\mathrm{Sn}-\mathrm{X}_{\mathrm{ax}}$ bonds, and (ii) angular distortion: the equatorial $\mathrm{X}_{\mathrm{eq}}-\mathrm{Sn}-\mathrm{X}_{\mathrm{eq}}$ angle is smaller than $120^{\circ}$ and the $\mathrm{X}_{\mathrm{aq}}-\mathrm{Sn}-\mathrm{X}_{\mathrm{aq}}$ angle is smaller than $180^{\circ}$, values expected in the regular trigonal bipyramid. This is the same as the $\mathrm{SnX}_{4} \mathrm{E}$ trigonal bipyramidal coordination in Galy-Andersson's model [20];

- E model (Fig. 4e): only one X atom is pushed away by the lone pair and it results in a $\mathrm{SnX}_{5} \mathrm{X}^{\prime}$ coordination, that is a $\mathrm{SnX}_{5}$ square pyramid (octahedral electron pair geometry, including the lone pair), since the $\mathrm{X}^{\prime}$ atom is pushed far away from being a bonding distance. High repulsions by the lone pairs result in distortions on bond lengths and bond angles: (i) the $\mathrm{Sn}-\mathrm{X}_{\mathrm{ax}}$ bond is very significantly shorter than the four equatorial $\mathrm{Sn}-\mathrm{X}_{\mathrm{eq}}$ bonds, and (ii) the $\mathrm{X}_{\mathrm{ax}}-\mathrm{Sn}-\mathrm{X}_{\mathrm{eq}}$ and non-diagonal $\mathrm{X}_{\mathrm{eq}}-\mathrm{Sn}-\mathrm{X}_{\mathrm{eq}}$ bond angles are lower than the $90^{\circ}$ expected for the regular octahedral electron pair geometry. This corresponds to the $\mathrm{SnX}_{5} \mathrm{E}$ octahedral geometry in Galy-Andersson's model [20].

- $B$ and $D$ models: the large disturbance created by the lone pair creates strictly the regular $C, A$, or $E$ model only if the site symmetry of the central atom requires it. The regular $C$ model requires a 3 -fold axis along the $\mathrm{Sn}-\mathrm{E}$ axis, and it has three equal bond lengths and three equal bond angles. The regular A model requires a 2 -fold axis along the Sn-E axis, along the intersecting line of two normal mirrors, and it has two equal equatorial bond lengths, two equal axial bond lengths, and four equal axial to equatorial $\mathrm{X}_{\mathrm{ax}}-\mathrm{Sn}-\mathrm{X}_{\mathrm{eq}}$ bond angles. The regular $E$ model requires a 4 -fold axis along the $\mathrm{Sn}-\mathrm{E}$ axis, and it has four equal equatorial bond lengths, four equal axial to equatorial $\mathrm{X}_{\mathrm{ax}}-\mathrm{Sn}-\mathrm{X}_{\mathrm{eq}}$ bond angles and two equal non-diagonal $\mathrm{X}_{\mathrm{eq}}-\mathrm{Sn}-\mathrm{X}_{\mathrm{eq}}$ equatorial angles. Lower local symmetry results in further distortions. Some of these can be small and the coordination can be considered to be close enough to one of the regular models. However, distortions can be much larger and even the number of $\mathrm{X}^{\prime}$ atoms really pushed away by the lone pair can be difficult to define. Often, one or more atoms are sufficiently far to be counted as not being a covalent bond but still not far enough to be neglected and they form "weaker bonds". In order to account for many of these unclear cases, Brown's description includes two additional models, $B$ and $D$, that are intermediates between the $C, A$, or $E$ models. The $B$ model (Fig. $4 \mathrm{~b}$ ) accounts for cases intermediate between models $C$ and $A$, i.e. between the $\mathrm{SnX}_{3}$ trigonal pyramid and the $\mathrm{SnX}_{4}$ seesaw, therefore the coordination, $\mathrm{SnX}_{3} \mathrm{X}$, is intermediate between these, where the last $\mathrm{X}$ is neither close enough to tin to be a covalent bond nor far enough to be neglected. Similarly, the $D$ model (Fig. $4 \mathrm{~d}$ ) for $\mathrm{SnX}_{4} \mathrm{X}$ is intermediate between the $\mathrm{SnX}_{4}$ seesaw and the $\mathrm{SnX}_{5}$ square pyramid. The uncertainty on the number of $\mathrm{X}$ non-metal atoms that form a covalent bond to the central atom also makes it difficult to assign a hybridization scheme. Should a non-negligible "weak-bond" count to be using a hybrid orbital, although it is clearly much weaker than a normal covalent bond, yet much too close to be neglected? In addition, the presence of one or more extra atoms forming weak bonds changes dramatically the value of the bond angles. Some coordinations do not obey the VSEPR model, such as in $\mathrm{SnO}$ [23], no electron pair geometry can be defined, and neither can be the symbols in the Galy-Andersson model or in the Brown model. In such cases, the lattice energy compensates for the higher local energy at tin due to the VSEPR model not being obeyed.

\subsubsection{Tin(II) electronic structure, bonding type and Mössbauer spectroscopy}

Tin-119 has the same nuclear spin as iron-57, 1/2 in the ground state and $3 / 2$ in the first excited state therefore, in the absence of magnetic interactions, only one line per site is observed if there are no quadrupolar interactions. This is the case of Fig. 5a and c. On the contrary, in the case of Fig. 5b, a large quadrupole splitting is observed, due to the interactions of the quadrupole moment of the ${ }^{119} \mathrm{Sn}$ nucleus in the $3 / 2$ spin state with the electric field gradient (e.f.g.) generated by the electric environment of tin. Calcium stannate $\mathrm{CaSnO}_{3}$ has the perovskite structure, hence tin is present in the form of $\mathrm{Sn}^{4+}$ stannic ions in octahedral coordination, i.e. there is no e.f.g. generated by the surrounding atoms/ions $\left(\left(V_{z z}\right)_{\text {latt }}=0\right)$. The $\mathrm{Sn}^{4+}$ ion has the $[\mathrm{Kr}] 4 d^{10}$ electronic structure. All orbitals that contain electrons are full and are in the core, and all the valence electrons have been lost, therefore there is no e.f.g. due to valence electrons $\left(\left(V_{z z}\right)_{\text {val }}=0\right)$, hence the total $V_{z z}=0$. In addition, $\mathrm{CaSnO}_{3}$ is taken as the reference of isomers shifts therefore, with in addition no quadrupolar interactions, it gives a single line at $0 \mathrm{~mm} / \mathrm{s}$ (Fig. 5a). $\mathrm{CsSnBr}_{3}$ has also the perovskite structure, thus tin is in the form of $\mathrm{Sn}^{2+}$ stannous ions located in octahedral coordination, and it results that 
$\left(V_{z z}\right)_{\text {latt }}=0$. However, in contrast with $\mathrm{CaSnO}_{3}$, in $\mathrm{CsSnBr}_{3}$ tin is in the divalent state and the stannous ion has the $[\mathrm{Kr}] 4 d^{10} 5 s^{2}$ electronic structure, the $5 p$ electron being lost by ionization. In addition to the core electrons, there are two valence electrons, however they are on the $5 s$ orbitals, and since $s$ orbitals are spherical, they generate no e.f.g. $\left(\left(V_{z z}\right)_{\mathrm{val}}=0\right)$, hence the total $V_{z z}=0$ and there results a single line (Fig. 5c). The spherical lone pair is non-stereoactive, bonding at tin is ionic, and this generates no quadrupole splitting. The $5 s$ orbital is not shared since there is no orbital hybridization and it does not participate in bonding. This makes it that the valence $s$ electron density acting at the tin nucleus is high and this results in a large isomer shift, hence a single line (since $V_{z z}=0$ ) at $\approx 4.1 \mathrm{~mm} / \mathrm{s}$ (Fig. $5 \mathrm{c}$ ). When bonding in $\operatorname{tin}(\mathrm{II})$ is covalent, the lone pair is stereoactive, therefore the coordination is incomplete and highly distorted and this results in a large $\left(V_{z z}\right)_{\text {latt }}$. In addition, since the tin orbitals are hybridized, the non-spherical orbitals $5 p$, and $5 d$ when the octet is exceeded, contribute to form a large $\left(V_{z z}\right)_{\mathrm{val}}$. Since the contribution of the valence electrons to the quadrupolar interactions is much larger than that of the lattice, i.e. $\left|\left(V_{z z}\right)_{\text {val }}\right| \gg \mid\left(V_{z z}\right)_{\text {latt }}$, the former predominates, regardless of the value and sign of the Sternheimer shielding and antishielding factors. Therefore, a large quadrupole doublet centered at 3.0$3.6 \mathrm{~mm} / \mathrm{s}$ is observed (Fig. $5 \mathrm{~b}$ ).

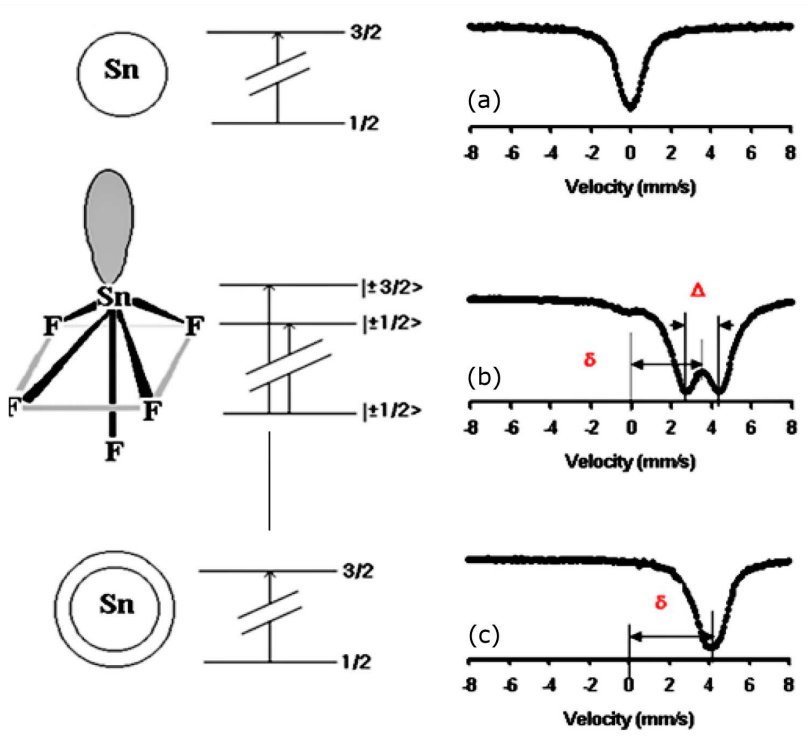

Fig. 5. Mössbauer spectra for (a) $\mathrm{CaSnO}_{3}$, (b) covalently bonded $\mathrm{Sn}(\mathrm{II})$ in $\mathrm{BaSnF}_{4}$, and (c) ionic $\mathrm{Sn}^{2+}$.

It results that ${ }^{119} \mathrm{Sn}$ Mössbauer spectroscopy is a very useful tool for probing the divalent tin bonding type, lone pair stereoactivity, and orbital hybridization. It is particularly helpful in cases when the information obtained from the crystallographic methods have limitations, like the cases studied in this work, in order to attempt to understand how divalent tin, expected to give covalent bonding to fluorine, can combine with fluorite-type ionic structures to give stable structures. In such cases, much more complete conclusions can be obtained by combining the results of both techniques.

\section{Results and discussion}

\subsection{The ordered structure of $\alpha-\mathrm{PbSnF}_{4}$ and $\mathrm{BaSnF}_{4}$}

The X-ray powder diffraction pattern of $\alpha-\mathrm{PbSnF}_{4}$ (Fig. 6b) is easily indexed to be a tetragonal distortion of the cubic structure of $\beta-\mathrm{PbF}_{2}$ (Fig. 6a). It should be noted that further lattice distortion to orthorhombic can also be obtained (Fig. 6c), however this will not be studied further here. The relationship between the Miller indices of the Bragg peaks of $\beta-\mathrm{PbF}_{2}$ and of $\alpha-\mathrm{PbSnF}_{4}$ leads to the following conclusions:

- there is a tetragonal distortion;

- The F (face centered) lattice translations of the fluorite-type structure have disappeared to give a $\mathrm{P}$ (primitive) lattice;

- the periodicity along the $c$ axis of the unit-cell is doubled;

- there is a $45^{\circ}$ rotation of the $a$ and $b$ axes around the $c$ axis.

The relationship between the unit-cell axes of the two structures is shown in Fig. 7. They are related as follows: $\beta-\mathrm{PbF}_{2}$ or $\mathrm{BaF}_{2}(a, b, c) \Rightarrow \alpha-\mathrm{PbSnF}_{4}$ or $\mathrm{BaSnF}_{4}(a / \sqrt{ } 2, a / \sqrt{ } 2,2 c)$.

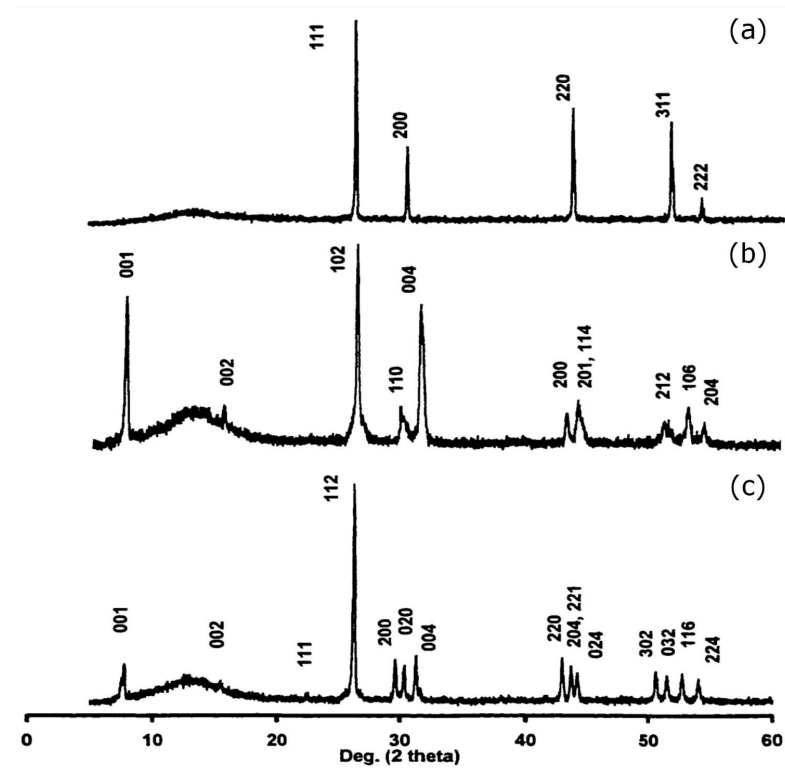

Fig. 6. X-ray powder diffraction of $\beta-\mathrm{PbF}_{2}$ and $\mathrm{PbSnF}_{4}$ : (a) $\beta-\mathrm{PbF}_{2}$, (b) $\alpha-\mathrm{PbSnF}_{4}(a q 1)$ (tetragonal) prepared by precipitation from lead(II) nitrate and tin(II) fluoride without $\mathrm{HF}$, and (c) $\mathrm{o}-\mathrm{PbSnF}_{4}$ (orthorhombic) prepared by precipitation from lead(II) nitrate and tin(II) fluoride using HF. 


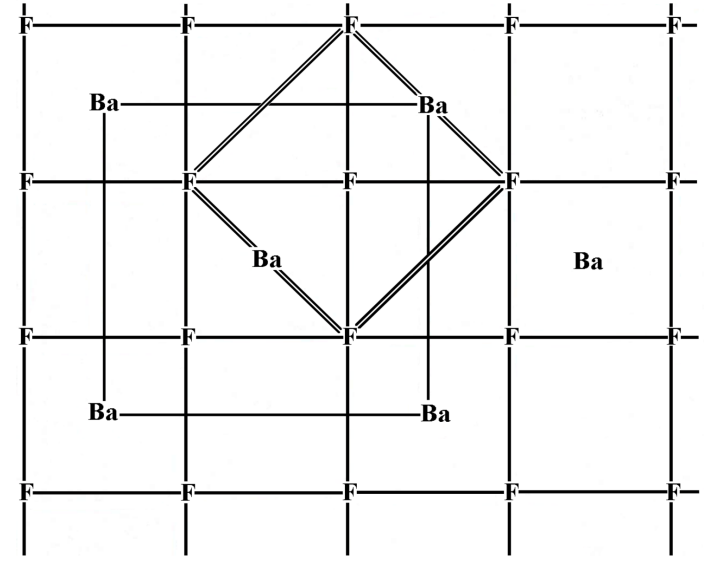

Fig. 7. Relationship between the unit-cell axes of $\mathrm{BaF}_{2}$ (face centered $(a, b)$ face with $\mathrm{Ba}$ at the corners) and of $\mathrm{BaSnF}_{4}$ (primitive $(a, b)$ face with $\mathrm{F}$ at the corners and $\mathrm{Ba}$ on two faces). The direction of the $c$ axis, perpendicular to the figure, is unchanged however the periodicity is doubled.
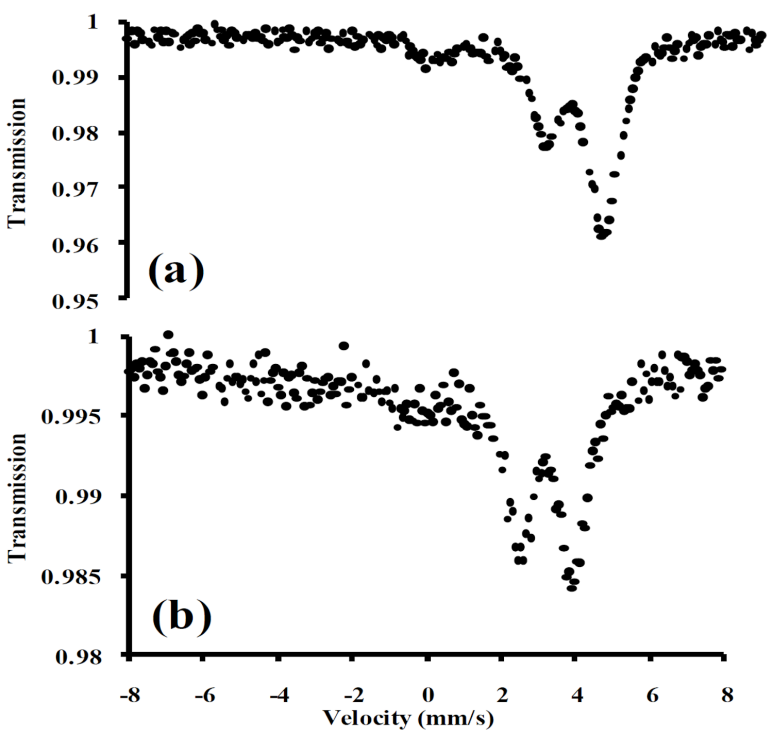

Fig. 8. Ambient temperature Mössbauer spectra of highly oriented $\alpha-\mathrm{PbSnF}_{4}$ : change of the asymmetry of the quadrupole doublet with the orientation of the sample relative to the $\gamma$-ray beam direction: (a) $\theta=0^{\circ}$ ( $\gamma$-ray beam perpendicular to the sample), (b) $\theta=45^{\circ}$. $\theta$ is the angle between the $\gamma$-ray beam and the normal to the plane of the sample.

The samples suffer from a very acute case of preferred orientation, as expected by the crystallite twodimensional shape in the form of large sheets that crumble as soon as one tries to isolate some. It is not possible to reduce the preferred orientation by milling since this results in a phase transition giving a disordered nanophase instead of the same phase with less or no preferred orientation [25]. It was therefore impossible to get a suitable single crystal for single crystal X-ray diffraction or a polycrystalline sample with sufficiently reduced preferred orientation to use the Rietveld method. The X-ray powder diffraction pattern (Fig. 6b) shows that all (001) peaks are strongly enhanced while the $(h 00)$ and $(h k 0)$ peaks are much depressed, suggesting that the cleavage planes are perpendicular to the $c$ axis of the unit-cell, hence parallel to the $(a, b)$ plane.

The preferred orientation of a sample of $\alpha-\mathrm{PbSnF}_{4}$ was enhanced by filtering the precipitate by suction and allowing it to dry in the Buchner funnel, and then it was removed from there without any disturbance and placed in the Mössbauer holder. The spectrum was recorded versus the orientation of the sheet in the $\gamma$-ray beam. The spectrum is a large quadrupole doublet with an isomer shift $\delta=3.24(1) \mathrm{mm} / \mathrm{s}$ and a quadrupole splitting $\Delta=1.57(2) \mathrm{mm} / \mathrm{s}$. These spectra are very much like that of Fig. 5b and confirm that the tin lone pair is stereoactive and that bonding is covalent with the lone pair being located on a hybrid orbital. It can be seen that when the $\gamma$-ray beam is perpendicular to the sheet, the Mössbauer doublet is highly asymmetric (Fig. 8a). When the sample is rotated at $45^{\circ}$ from the $\gamma$-ray beam, the asymmetry is reduced dramatically. Such a behavior is observed in single crystals and in highly oriented polycrystalline samples [26]. The ratio of the intensity of the two lines in a single crystal is the following:

$$
\frac{I_{3 / 2}(\theta)}{I_{1 / 2}(\theta)}=\frac{1+\cos ^{2} \theta}{2 / 3+\sin ^{2} \theta} \neq 1,
$$

whereas $\theta$ is the angle between the $\gamma$-ray beam and $V_{z z}$, the main axis of the e.f.g. acting at tin. The spectrum will be symmetrical when the following condition is met:

$$
\begin{gathered}
\left.I_{3 / 2}(\theta)=I_{1 / 2}(\theta) \rightarrow 1+\cos ^{2} \theta=2 / 3+\sin ^{2} \theta\right) \rightarrow \\
\theta=\arcsin (1 / \sqrt{ } 3)=54.74^{\circ} .
\end{gathered}
$$

For $\theta=54.74^{\circ}$, called the magic angle, the two lines will have the same intensity. It was not possible to measure a Mössbauer spectrum at $\theta=54.74^{\circ}$ because most of the $\gamma$-ray beam was absorbed by the sample and the sample holder at such a high grazing angle, however the spectrum measured at $45^{\circ}$ (Fig. 8b) is clearly much more symmetrical than at $\theta=0^{\circ}$. Obviously, at $54.74^{\circ}$, it would be close to symmetrical. This shows that at $\theta=0^{\circ}$, the $\gamma$-ray beam is parallel to $V_{z z}$, and since this direction is normal to the sheet, $V_{z z}$ is parallel to the $c$ axis. The main contributor to the e.f.g. is $\left(V_{z z}\right)_{\mathrm{val}}$, the imbalance in non-spherical valence electrons ( $p$ and $d$ electrons), $d$ due to the contribution of one or two $5 d$ orbitals to hybridization, and the lone pair, on a hybrid orbital, is the main contributor (Fig. 9). This proves that the tinlone pair axis is parallel to $c$, thereby creating sheets of lone pairs that are at the origin of the extreme case of two-dimensionality and the resulting extreme case of preferred orientation (Fig. 6b).

Finally, combining together the crystallographic and the Mössbauer data, a realistic model of the $\alpha-\mathrm{PbSnF}_{4}$ structure can be made. The relationship between the unit-cell axes of the fluorite-type structure and of $\alpha-\mathrm{PbSnF}_{4}$, and the doubling of the $c$ unit-cell parameter, require to have $\mathrm{M}(\mathrm{Pb}$ or $\mathrm{Ba})$ and $\mathrm{Sn}$ layers parallel to 
(a)
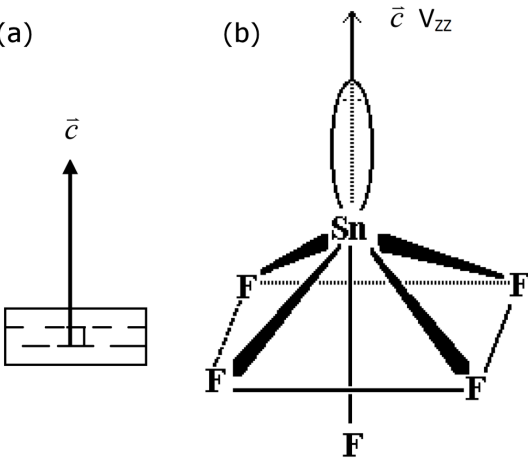

(c)

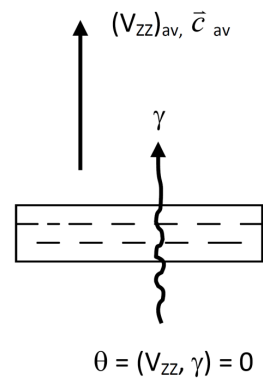

Fig. 9. Sample orientation of highly oriented $\alpha-\mathrm{PbSnF}_{4}$ in the $\gamma$-ray beam: (a) the $c$ axis is normal to sheet-like crystallites, (b) the $c$ axis is parallel to the lone pair axis and to $V_{z z}$, (c) $\theta=0$ in highly oriented $\alpha-\mathrm{PbSnF}_{4}$ when the $\gamma$-ray beam is normal to the sheets. (a)

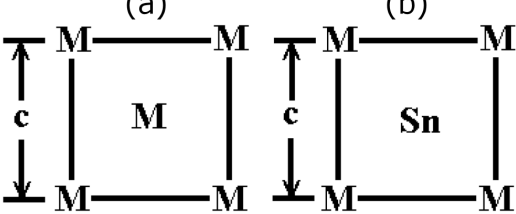

(c)

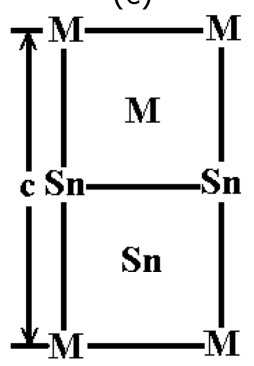

Fig. 10. M/Sn ordering in $\mathrm{MSnF}_{4}$ : (a) $\mathrm{MF}_{2}$, (b) $\mathrm{MSnF}_{4}$ first hypothesis (M Sn M ordering), (c) $\mathrm{MSnF}_{4}$ second hypothesis (M M Sn Sn M M ordering).

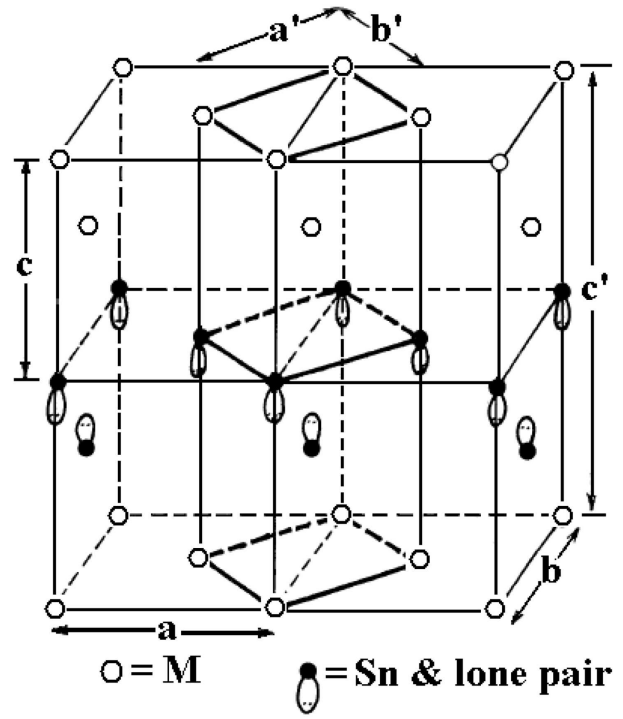

Fig. 11. Ordering of the type ... $\mathrm{Pb} \mathrm{Pb} \mathrm{Sn} \mathrm{Sn} \mathrm{Pb} \mathrm{Pb}$ ... required to double the $c$ parameter, with lone pairs squeezed between the two tin layers in order to give highly efficient cleavage, and still agree with the tetragonal symmetry of the unit-cell. Unit-cell axes: $\beta-\mathrm{PbF}_{2}$ cubic unit-cell $(a, b, c) ; \alpha-\mathrm{PbSnF}_{4}$ tetragonal unit-cell $\left(a^{\prime}, b^{\prime}, c^{\prime}\right)$. (a)

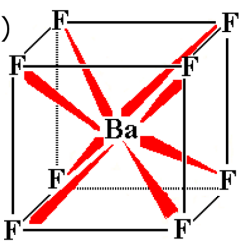

(b)

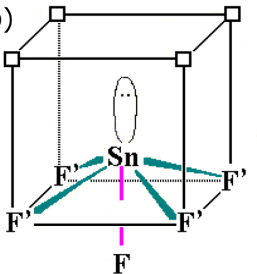

(c)

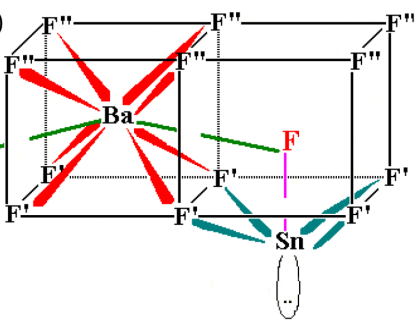

(d)

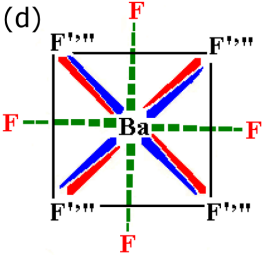

Fig. 12. Barium and tin coordination in $\mathrm{BaF}_{2}$ and in $\mathrm{BaSnF}_{4}$ : (a) $\mathrm{BaF}_{8}$ cube in $\mathrm{BaF}_{2}$, (b) $\mathrm{SnFF}_{4} \mathrm{E}$ pseudooctahedron in $\mathrm{BaSnF}_{4}$, (E = lone pair), (c) $\mathrm{BaF}_{4}^{\prime \prime} \mathrm{F}_{4}^{\prime} \mathrm{F}_{4}$ unit in $\mathrm{BaSnF}_{4}$, and (d) top view of the Barium coordination in $\mathrm{BaSnF}_{4}\left(\mathrm{~F}^{\prime}\right.$ and $\mathrm{F}^{\prime \prime}$ are superimposed).

the $(a, b)$ plane and ordered as follows: ... M M Sn Sn ... (Fig. 10). Combining this with the Mössbauer data, that showed the tin lone pairs are parallel to the $c$ axis, and the requirement of $\mathrm{Sn}$ to bind to $\mathrm{M}$ using $\mathrm{Sn}-\mathrm{F}-\mathrm{M}$ bridges, it is necessary to have the lone pairs of two adjacent tin layers pointing to a common sheet of lone pairs rather than pointing away from one another (Fig. 11). This results in the presence of sheets of lone pairs perpendicular to the $c$ axis, and since no efficient bonding can occur through these sheets, it results in a very highly two-dimensional structure, hence sheet-like crystallites, and a very high amount of preferred orientation. Neutron diffraction on a polycrystalline sample of isostructural $\mathrm{BaSnF}_{4}$, that suffers from less preferred orientation, confirmed these models and determined the positions of the fluoride ions (Fig. 1c) [27]. Figure 12 shows a three-dimensional view of the coordination of $\mathrm{Ba}^{2+}$ and of $\mathrm{Sn}$, and also of the links between the two polyhedra. It should be noted that the coordination of barium changes from 8 in $\mathrm{BaF}_{2}$ to 12 in $\mathrm{BaSnF}_{4}$, the four additional bonds being to the fluorine axially bonded to tin.

\subsection{Disordered structures}

of $\mathrm{SnF}_{2}$ with $\mathrm{CaF}_{2}$ and with $\mathrm{PbF}_{2}$

The X-ray powder diffraction pattern of the following new phases discovered in our laboratory is cubic fluoritetype, despite containing more than one metal. Some of these phases are stoichiometric, such as $\gamma-\mathrm{PbSnF}_{4}$, a non-quenchable high temperature phase, $\mathrm{PbSn}_{4} \mathrm{~F}_{10}$, metastable at ambient conditions, and nanocrystalline $\mu \gamma-\mathrm{PbSnF}_{4}$. Others are solid solutions and are therefore non-stoichiometric, $\mathrm{M}_{1-x} \mathrm{Sn}_{x} \mathrm{~F}_{2}(\mathrm{M}=\mathrm{Ca}$ and $\mathrm{Pb})$. Figures 13 and 14 show two examples of X-ray powder diffraction patterns. Figure 13 shows the diffraction pattern of the precipitate obtained when a solution of calcium nitrate is added to a solution of stannous fluoride, 


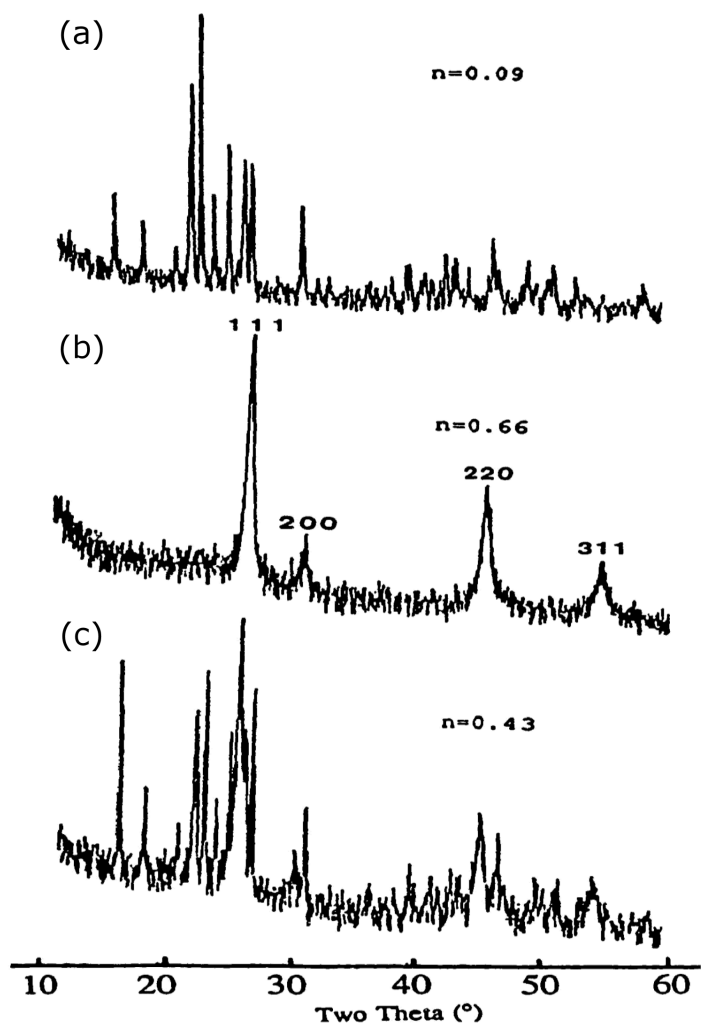

Fig. 13. X-ray powder diffraction pattern of the precipitate obtained versus the molar fraction $n$ of $\mathrm{Ca}\left(\mathrm{NO}_{3}\right)_{2(a q)}$ added to a solution of $\mathrm{SnF}_{2}$ : (a) $\mathrm{CaSn}_{2} \mathrm{~F}_{6}$, (b) $\mathrm{Ca}_{1-x} \mathrm{Sn}_{x} \mathrm{~F}_{2}(x \approx 0.30),\left(\right.$ c) a mixture of $\mathrm{CaSn}_{2} \mathrm{~F}_{6}$ and $\mathrm{Ca}_{1-x} \mathrm{Sn}_{x} \mathrm{~F}_{2}$.

versus the molar ratio $n$ of calcium nitrate in the reaction mixture. At low $n$ values, i.e. for reactions mixtures rich in $\mathrm{SnF}_{2}$, a stoichiometric phase that was determined by chemical analysis to be $\mathrm{CaSn}_{2} \mathrm{~F}_{6}$ was obtained. Its Xray powder diffraction pattern (Fig. 13a) is not related to that of the fluorite-type structure, therefore it will not be discussed further here. At high $n$ values, for reactions mixtures rich in calcium ions, the X-ray diffraction pattern (Fig. 13b) is the same as that of fluorite-type $\mathrm{CaF}_{2}$, (Fig. 14a), with significantly broadened lines, while for medium values of $n$, a mixture of the two phases is obtained (Fig. 13c). Chemical analysis of several precipitates that have the diffraction pattern of Fig. 13b showed that, for all of them, they contain no nitrate and that 20 to $30 \%$ of the calcium has been replaced with tin. Therefore, the precipitate of Fig. 13b is a $\mathrm{Ca}_{1-x} \mathrm{Sn}_{x} \mathrm{~F}_{2}$ solid solution. Applying the Scherrer formula to the linewidth corrected from instrumental broadening using the Warren formula, it was determined that the average diameter of the crystallites is $9 \mathrm{~nm}$, and therefore the material is nanocrystalline [28]. A wide $\mathrm{Pb}_{1-x} \mathrm{Sn}_{x} \mathrm{~F}_{2}$ solid solution $0 \leq x \leq 0.50$ was prepared by heating mixture of the two fluorides at $500^{\circ} \mathrm{C}$. It was found to have the cubic fluorite-type structure for $0 \leq x \leq 0.30$ and the tetragonal $\beta$ - $\mathrm{PbSnF}_{4}$ type for $0.30<x \leq 0.50$. The $\mathrm{Ca}_{1-x} \mathrm{Sn}_{x} \mathrm{~F}_{2}$ solid solution could not be prepared by the

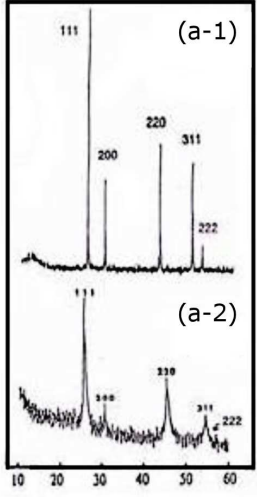

(a) Deg.(2theta) Kor Cu
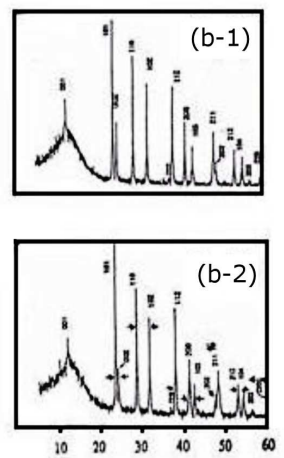

(b) Deg. (2theta) $\mathrm{K} \alpha \mathrm{Cu}$

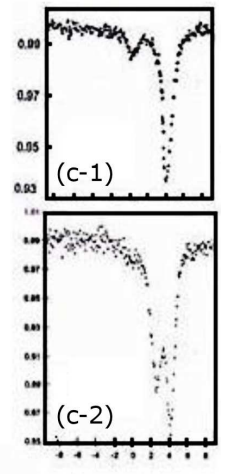

(c) Velocity (mu/s)
Fig. 14. (a): X-ray powder diffraction pattern of (a-1) $\mathrm{CaF}_{2}$ and $(\mathrm{a}-2)$ of $\mathrm{Ca}_{1-x} \mathrm{Sn}_{x} \mathrm{~F}_{2}(x=0.27)$, (b): X-ray powder diffraction pattern of (b-1) BaClF and (b-2) of $\mathrm{Ba}_{1-x} \mathrm{Sn}_{x} \mathrm{Cl}_{1+y} \mathrm{~F}_{1-y}(x=0.15, y=0.094)$, (c) ${ }^{119} \mathrm{Sn}$ ambient temperature Mössbauer spectrum of: (c-1) $\mathrm{Ba}_{1-x} \mathrm{Sn}_{x} \mathrm{Cl}_{1+y} \mathrm{~F}_{1-y}(x=0.15, y=0.094)$ and (c-2) $\mathrm{Ca}_{1-x} \mathrm{Sn}_{x} \mathrm{~F}_{2}(x=0.27)$.

same method. Instead, it decomposes to a mixture of $\mathrm{CaF}_{2}$ and $\mathrm{SnF}_{2}$ when heated. When $\alpha-\mathrm{PbSnF}_{4}$ is ballmilled, the superstructure peaks $((001)$ and $(002))$ and the peak splitting due to the tetragonal distortion (e.g. (110) and (004)) disappear rapidly to give the same list of peaks of the $\mathrm{F}$ lattice as for fluorite-type $\beta-\mathrm{PbF}_{2}$, while all peaks become broad (Fig. 15). The average crystallite diameter calculated from the line width at half height was $9 \mathrm{~nm}$. Therefore, the following order-disorder phase transition takes place rapidly (50-60 s) on ball-milling (b.m.):

$$
\begin{aligned}
& \text { crystalline ordered } \stackrel{\text { (b.m.) }}{\Longrightarrow} \text { nanocrystalline disordered } \\
& \alpha-\mathrm{PbSnF}_{4} \quad \mu \gamma-\mathrm{PbSnF}_{4}
\end{aligned}
$$

The absence of superstructure peaks and of peak splitting that would show there is a lattice distortion in both the solid solutions and the stoichiometric phases that have the cubic $\mathrm{F}$ lattice of the fluorite-type show that tin and the other metal ion $\left(\mathrm{Ca}^{2+}\right.$ or $\left.\mathrm{Pb}^{2+}\right)$ are randomly disordered on the same Wyckoff site of the Fm3m space group. If the two metals are disordered on the same site, they should have a similar size and the same bonding type, i.e. ionic bonding in the fluorite structure, in order to abide by the Hume-Rothery rules [29]. The size rule is violated in both cases, by $17 \%$ with $\mathrm{Ca}^{2+}$ and by $35 \%$ for $\mathrm{Pb}^{2+}$. If $\mathrm{Sn}$ substitutes $\mathrm{Ca}^{2+}$ or $\mathrm{Pb}^{2+}$ ions, $\mathrm{Sn}$ must be present in the form of $\mathrm{Sn}^{2+}$ ions in order to have the same bonding mode. However, divalent tin is known to form covalent bonding with fluorine. As shown in Fig. 5, Mössbauer spectroscopy can provide an unambiguous answer about the nature of $\mathrm{Sn}-\mathrm{F}$ bonding. The spectrum of the $\mathrm{Ca}_{1-x} \mathrm{Sn}_{x} \mathrm{~F}_{2}$ solid solution (Fig. 14c-2) and that of $\mathrm{Pb}_{1-x} \mathrm{Sn}_{x} \mathrm{~F}_{2}$ (Fig. 16b) show clearly a quadrupole characteristic of covalent bonding. The same is true for nanocrystalline $\mu \gamma-\mathrm{PbSnF}_{4}$ obtained by ball-milling (Fig. 17e). It should be noted that the broad peak at $c a .0 \mathrm{~mm} / \mathrm{s}$ is due to amorphous $\mathrm{SnO}_{2}$ 
(a)

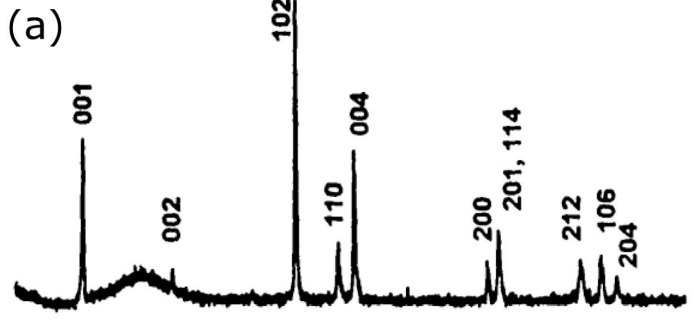

(b)

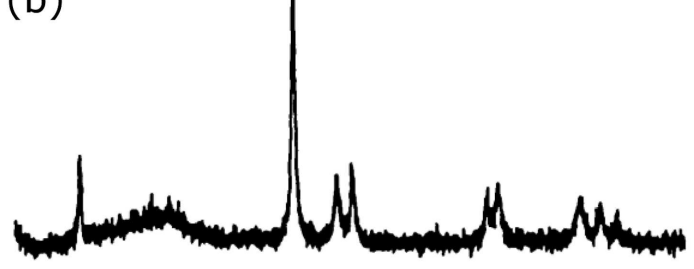

(c)

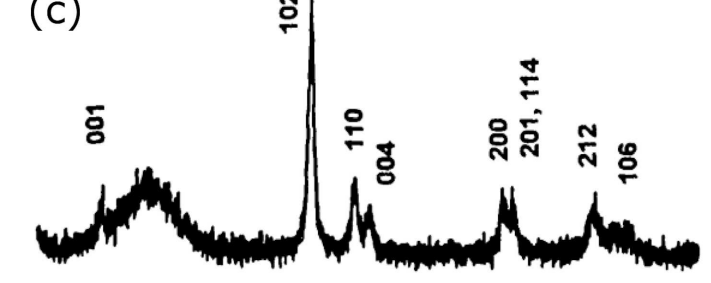

(d)
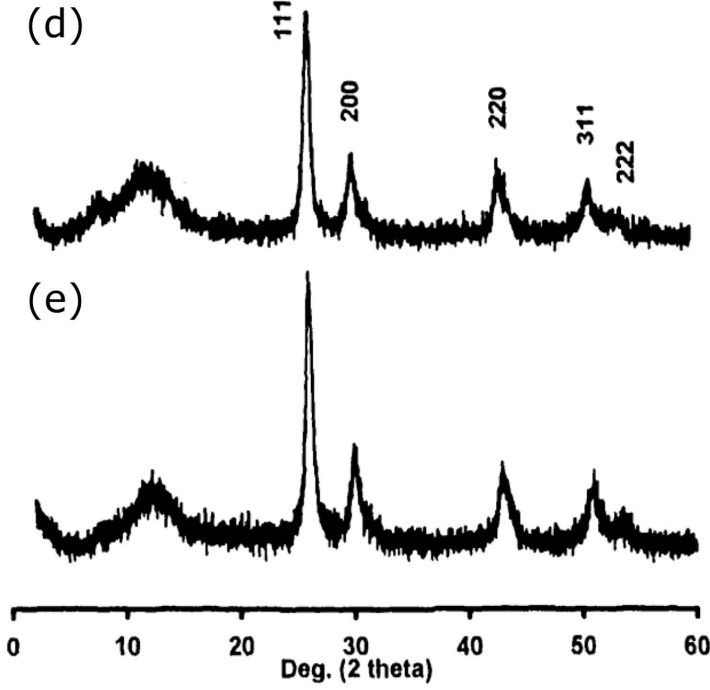

Fig. 15. X-ray powder diffraction pattern of $\alpha-\mathrm{PbSnF}_{4\left(a q_{1}\right)}$ subjected to ball-milling, versus ball-milling time: (a) not milled, (b) $10 \mathrm{~s}$, (c) $20 \mathrm{~s}$, (d) $50 \mathrm{~s},(\mathrm{e}) 60 \mathrm{~s}$.

due to surface oxidation of the particles [30]. The contribution of this peak to the total spectrum is much higher than the proportion of $\mathrm{SnO}_{2}$ in the sample, because its recoil-free fraction is about 20 times as high as that of tin(II) fluorides. The X-ray diffraction and the Mössbauer results appear to give contradictory results: on the one hand, the structure is ionic fluorite-type (diffraction), and on the other hand, Sn-F bonds are covalent (Mössbauer), and in addition, the Hume-Rothery rules state that both metals disordered in the structure, Sn and $\mathrm{Ca}$ (or $\mathrm{Pb}$ ) must use the same mode of bonding.

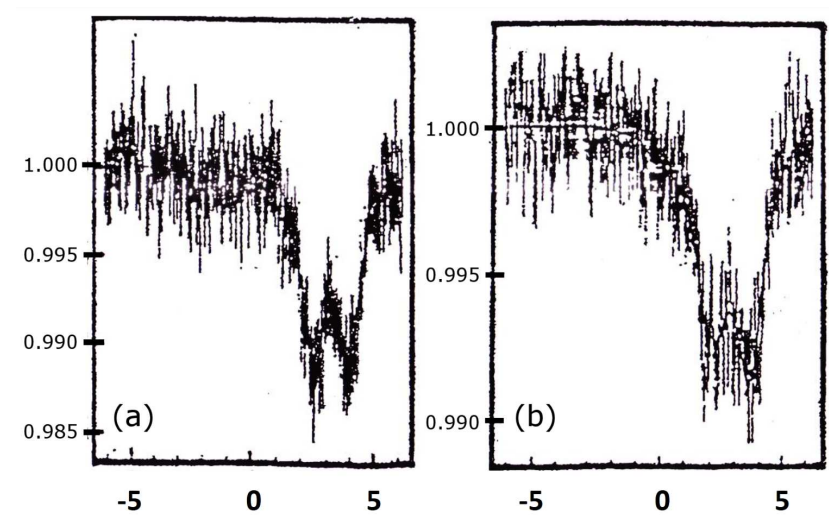

Fig. 16. Ambient temperature ${ }^{119} \mathrm{Sn}$ Mössbauer spectrum of (a) $\beta-\mathrm{PbSnF}_{4}$ and (b) $\mathrm{Pb}_{0.70} \mathrm{Sn}_{0.30} \mathrm{~F}_{2}$.

Figures 18 and 19 show attempts to fit covalent bonded tin in the $\mathrm{MF}_{2}$ fluorite structure, on the $\mathrm{M}^{2+}$ site, while abiding with the $m 3 m / O_{h}$ point symmetry of the site, i.e. in cubic or octahedral symmetry. In both cases, the tin lone pair is repeated by the site symmetry to generate eight lone pairs (Fig. 18) or six lone pairs (Fig. 19). Since tin has enough electrons for only one lone pair, none of these models is realistic, and in addition, none of these models provides opportunities for tin to make bonds with fluorine. It is very likely that each tin atom is located inside a $\left[\mathrm{F}_{8}\right]$ cube of the fluoride ion sublattice present in the fluorite structure, and forms bonds to one face only, to form four $\mathrm{Sn}-\mathrm{F}$ bonds, with a square pyramidal coordination and a square pyramidal electron pair geometry (Fig. 20a). This is similar to the tin coordination in the tetragonal $\mathrm{MSnF}_{4}(\mathrm{M}=\mathrm{Ba}$ and $\mathrm{Pb})$, except that the axial fluorine has moved to the corner of the $\left[\mathrm{F}_{8}\right]$ cube that are vacant in $\mathrm{MSnF}_{4}$ (Fig. 20b). The square pyramidal electron pair geometry is not favored by the VSEPR model for five electron pairs, however it can be stabilized by the lattice energy in order to satisfy the requirements of the crystal symmetry, like in $\mathrm{SnO}$, and for lead(II), in red $\mathrm{PbO}$, litharge [22, 23]. However, in order to avoid creating six lone pairs (Fig. 19), the tin atoms must be shifted away from the center of the $\left[\mathrm{F}_{8}\right]$ cube, along the tin-lone pair axis, thereby changing its point symmetry from $m 3 m$ to $4 \mathrm{~mm}$. In addition, the shift of the tin atom must be toward the face of the cube it form bonds to, in order to give room for the lone pair on the other side. This results in the model of Fig. 21. In order to agree with the cubic symmetry of the lattice and the absence of superstructure, two types of disorders must be present:

- a positional disorder: the two metals, Sn and Ca or $\mathrm{Pb}$ must be randomly disordered on the metal ion site;

- an orientational disorder: the tin-lone pair axis must point randomly towards any of the six faces of the $\left[\mathrm{F}_{8}\right]$ cube in order to avoid creating a privileged direction and to maintain an averaged cubic symmetry. 

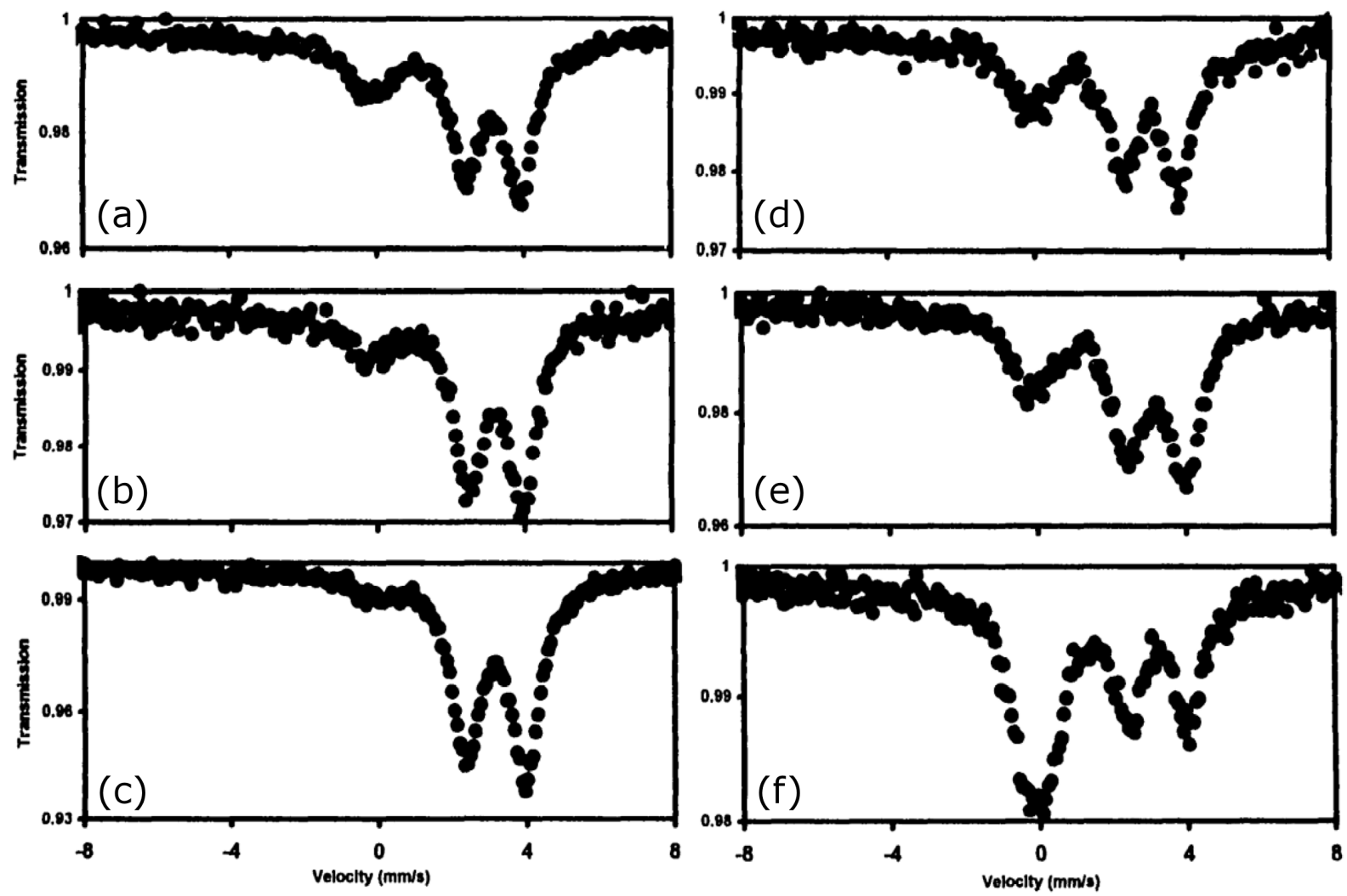

Fig. 17. Ambient temperature ${ }^{119} \mathrm{Sn}$ Mössbauer spectrum of (a) $\alpha-\mathrm{PbSnF}_{4\left(a q_{1}\right)}$, (b) $\alpha-\mathrm{PbSnF}_{4(s s r)},(\mathrm{c})$ o- $\mathrm{PbSnF} 4$, (d) $\beta-\mathrm{PbSnF}_{4}$, (e) $\mu \gamma-\mathrm{PbSnF}_{4}$, (f) non-oriented $\alpha-\mathrm{PbSnF}_{4}$ obtained by annealing $\mu \gamma-\mathrm{PbSnF}_{4}$ for $2 \mathrm{~h}$ at $200^{\circ} \mathrm{C}$.
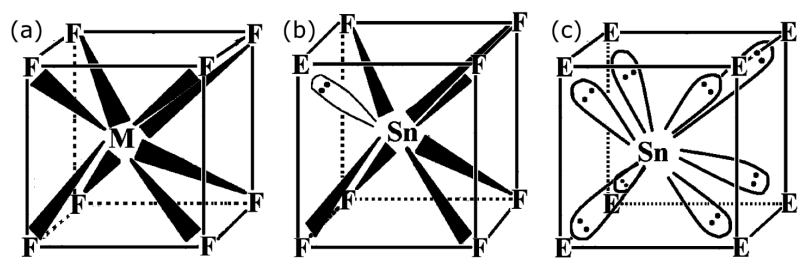

Fig. 18. Repetition of a stereoactive lone pair by the cubic symmetry of disordered fluorite-type systems: (a) $\left[\mathrm{MF}_{8}\right]$ cube in fluorite-type $\mathrm{MF}_{2}$, (b) $\left[\mathrm{SnEF}_{7}\right]$ polyhedron when the tin lone pair pushes one fluoride ion away, (c) the $m 3 m / O_{h}$ local symmetry of the tin site generates a total of eight lone pairs.
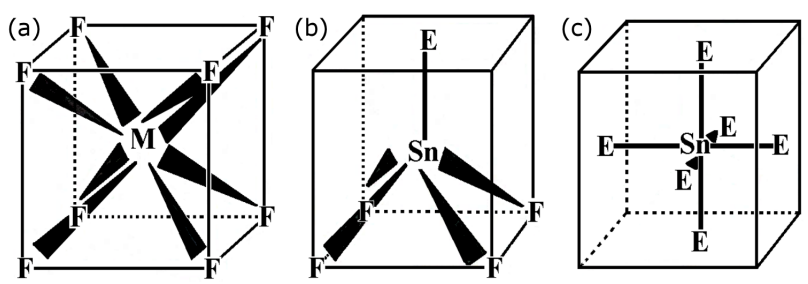

Fig. 19. Repetition of a stereoactive lone pair by the cubic symmetry of disordered fluorite-type systems: (a) $\left[\mathrm{MF}_{8}\right]$ cube in fluorite-type $\mathrm{MF}_{2}$, (b) $\left[\mathrm{SnEF}_{4}\right]$ polyhedron when the tin lone pair points towards a face and pushes four fluoride ions away (not shown), (c) the $\mathrm{m} 3 \mathrm{~m} / \mathrm{O}_{h}$ local symmetry at the tin site generates a total of six lone pairs.
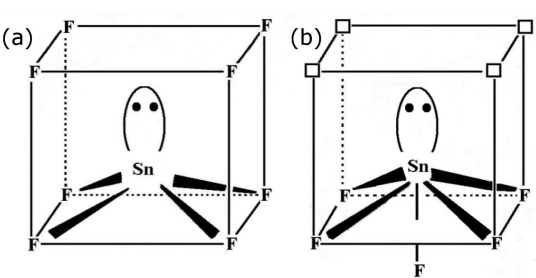

Fig. 20. (a) Model of the tin $\left[\mathrm{SnF}_{4} \mathrm{E}\right]$ square pyramidal electron pair geometry and a $\left[\mathrm{SnF}_{4}\right]$ square pyramidal coordination in the cubic disordered systems, and (b) model of the tin $\left[\mathrm{SnF}_{5} \mathrm{E}\right]$ octahedral electron pair geometry and a $\left[\mathrm{SnF}_{5}\right]$ square pyramidal coordination in ordered tetragonal $\mathrm{MSnF}_{4}(\mathrm{M}=\mathrm{Ba}$ and $\mathrm{Pb})$.

Therefore, for a $\mathrm{M}_{1-x} \mathrm{Sn}_{x} \mathrm{~F}_{2}$ composition, the average unit-cell contains in each metal site $100(1-x) \% \mathrm{M}$ and $100 x \% \mathrm{Sn}$, while $100 x / 6 \%$ lone pair point toward each of the six faces of the $\left[\mathrm{F}_{8}\right]$ cube that coordinates the metal site.

\subsection{The doubly disordered $B a_{1-x} S_{x} C l_{1+y} F_{1-y}$ solid solution}

When an aqueous solution of $\mathrm{BaCl}_{2} \cdot 2 \mathrm{H}_{2} \mathrm{O}$ is added to a solution of $\mathrm{SnF}_{2}(\mathrm{Ba} \rightarrow \mathrm{Sn})$, or vice-versa $(\mathrm{Sn} \rightarrow \mathrm{Ba})$ upon stirring, versus the molar ratio $X$ of barium chloride in the reaction mixture, four different types of precipitates were obtained: 


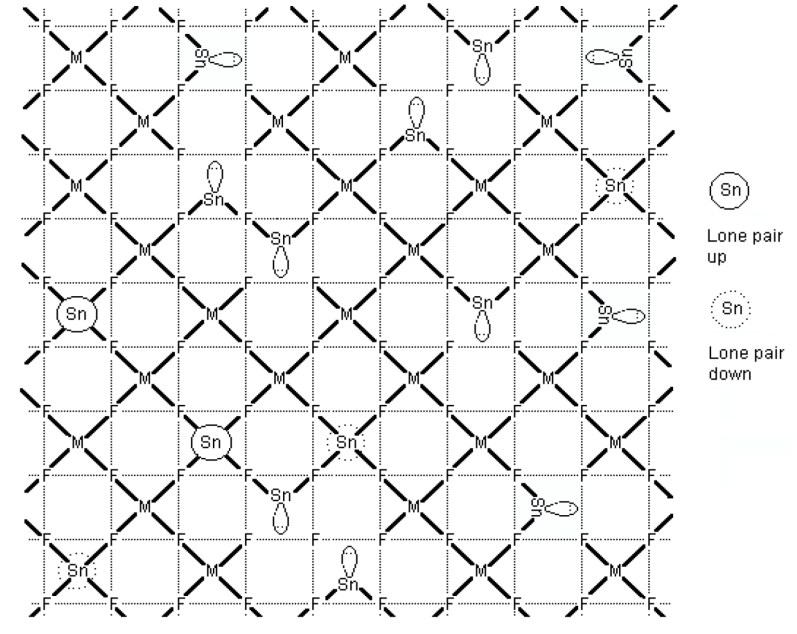

Fig. 21. Structural model of the disordered M/Sn/F phases: the tin lone pair points randomly toward any of the six faces of the $\left[\mathrm{F}_{8}\right]$ cube.

- $X \leq 0.10$ : pure $\mathrm{BaSn}_{2} \mathrm{~F}_{6}$, already known [31];

- $0.34 \leq X \leq 0.40$ : pure $\mathrm{BaSn}_{2} \mathrm{Cl}_{2} \mathrm{~F}_{4}$, a new phase;

- $0.52 \leq X \leq 0.80$ : pure $\mathrm{BaSnClF}_{3} \cdot 0.8 \mathrm{H}_{2} \mathrm{O}$, a new phase;

- $X>0.85$ : a pure "BaClF" like phase, a new phase.

Mixtures of phases were obtained for $X$ values in between these. The stoichiometry of each pure phase was established by elemental analysis and the degree of hydration of $\mathrm{BaSnClF}_{3} \cdot 0.8 \mathrm{H}_{2} \mathrm{O}$ by thermogravimetry. Only the "BaClF" like phase is of interest to us here. Its Xray powder diffraction pattern contains the same set of the Bragg peaks as that of $\mathrm{BaClF}$ with some lineshifts that show a $0.91 \%$ decrease of the unit-cell parameter $a$ and a $0.97 \%$ increase of the $c$ parameter, with a $0.86 \%$ decrease of the unit-cell volume (Fig. 22). Its chemical composition was found to be variable for both the metals and the halogens, therefore it is a non-stoichiometric solid that has the $\mathrm{BaClF}$ structure, hence its chemical formula can be written in the form of a doubly substituted solid solution, $\mathrm{Ba}_{1-x} \mathrm{Sn}_{x} \mathrm{Cl}_{1+y} \mathrm{~F}_{1-y}$. Elemental analysis of several samples showed the following variation of the chemical composition: $0<x \leq 0.15$ and $0 \leq y \leq 0.15$. The ${ }^{119} \mathrm{Sn}$ Mössbauer spectra (large quadrupole doublet at an isomer shift around $3 \mathrm{~mm} / \mathrm{s}$ ) show that tin is covalently bonded in $\mathrm{BaSn}_{2} \mathrm{Cl}_{2} \mathrm{~F}_{4}$ and in $\mathrm{BaSnClF}_{3} \cdot 0.8 \mathrm{H}_{2} \mathrm{O}$, while the broad line near $4 \mathrm{~mm} / \mathrm{s}$ for the $\mathrm{Ba}_{1-x} \mathrm{Sn}_{x} \mathrm{Cl}_{1+y} \mathrm{~F}_{1-y}$ solid solution shows that it contains tin(II) with ionic bonding in a distorted environment (Fig. 23). The $\mathrm{Ba}_{1-x} \mathrm{Sn}_{x} \mathrm{Cl}_{1+y} \mathrm{~F}_{1-y}$ solid solution was also prepared by the dry method at high temperature, by reaction of appropriate amounts of $\mathrm{BaF}_{2}$, $\mathrm{BaCl}_{2}$ and $\mathrm{SnF}_{2}$. This method makes it possible to control the stoichiometry of the solid solution and no elemental analysis is necessary. Figure 24 shows the domain of a pure solid solution in the $(x, y)$ plane. A pure $\mathrm{Ba}_{1-x} \mathrm{Sn}_{x} \mathrm{Cl}_{1+y} \mathrm{~F}_{1-y}$ solid solution was obtained within

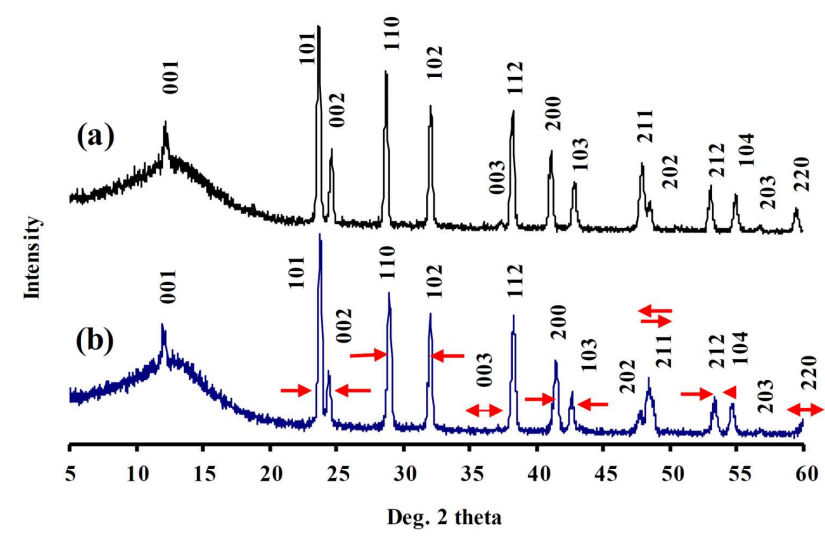

Fig. 22. X-ray powder diffraction pattern of: (a) unsubstituted $\mathrm{BaClF}$, (b) precipitated $\mathrm{Ba}_{1-x} \mathrm{Sn}_{x} \mathrm{Cl}_{1+y} \mathrm{~F}_{1-y}$ solid solution. The arrows show the line shift relative to non-substituted $\mathrm{BaClF}$.

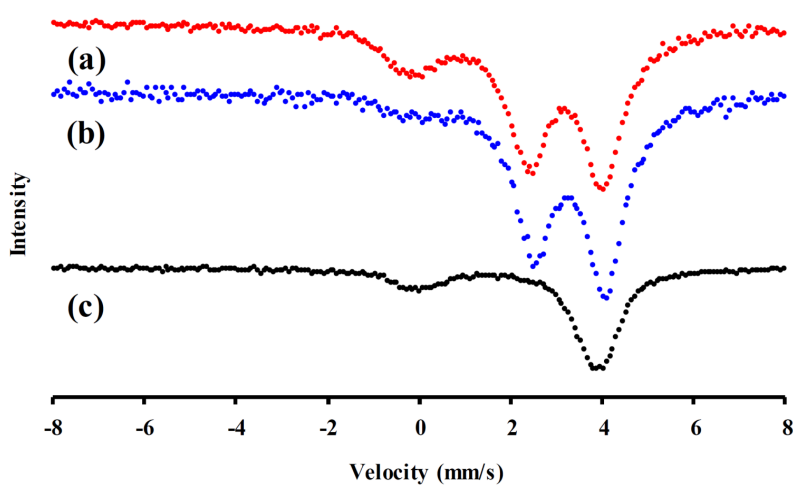

Fig. 23. Ambient temperature ${ }^{119} \mathrm{Sn}$ Mössbauer spectrum of precipitated (a) $\mathrm{BaSn}_{2} \mathrm{Cl}_{2} \mathrm{~F}_{4}$, (b) $\mathrm{BaSnClF}_{3}$. $0.8 \mathrm{H}_{2} \mathrm{O}$, (c) $\mathrm{Ba}_{1-x} \mathrm{Sn}_{x} \mathrm{Cl}_{1+y} \mathrm{~F}_{1-y}$ solid solution.

the following limits: $0 \leq x \leq 0.25$ and $-0.15 \leq y \leq 0.15$. All give the same X-ray diffraction pattern as $\mathrm{BaClF}$, although hardly with any significant line shift, hence no change of unit-cell parameters. The ambient temperature Mössbauer spectrum of a large number of samples was recorded, versus $x$ and $y$. Figure 25 shows the influence of $y$ at a fixed $x$ value. It is observed that for negative $y$ values $(\mathrm{F} / \mathrm{Cl}>1)$, a highly asymmetrical spectrum is obtained (Fig. 25a). When $y$ increases to less negative values, i.e. there is a smaller excess of $\mathrm{F}$, the asymmetry of the spectrum increases, and at positive $y$ values $(\mathrm{Cl} / \mathrm{F}$ $>1$ ), only one line at $c a .4 \mathrm{~mm} / \mathrm{s}$ is observed (Fig. 25b). In addition, the spectrum becomes weaker and weaker, such as nearly to escape detection at the most positive $y$ values. Cooling the sample of Fig. 25b to $17 \mathrm{~K}$ results in a very dramatic increase of the intensity of the spectrum (Fig. 25c). These observations lead to the following model of the $\mathrm{Ba}_{1-x} \mathrm{Sn}_{x} \mathrm{Cl}_{1+y} \mathrm{~F}_{1-y}$ solid solution (Fig. 26):

(a) X-ray diffraction shows that the structure is the same as that of non-substituted $\mathrm{BaClF}$ (since it is the same diffraction pattern), with no further lattice distor- 


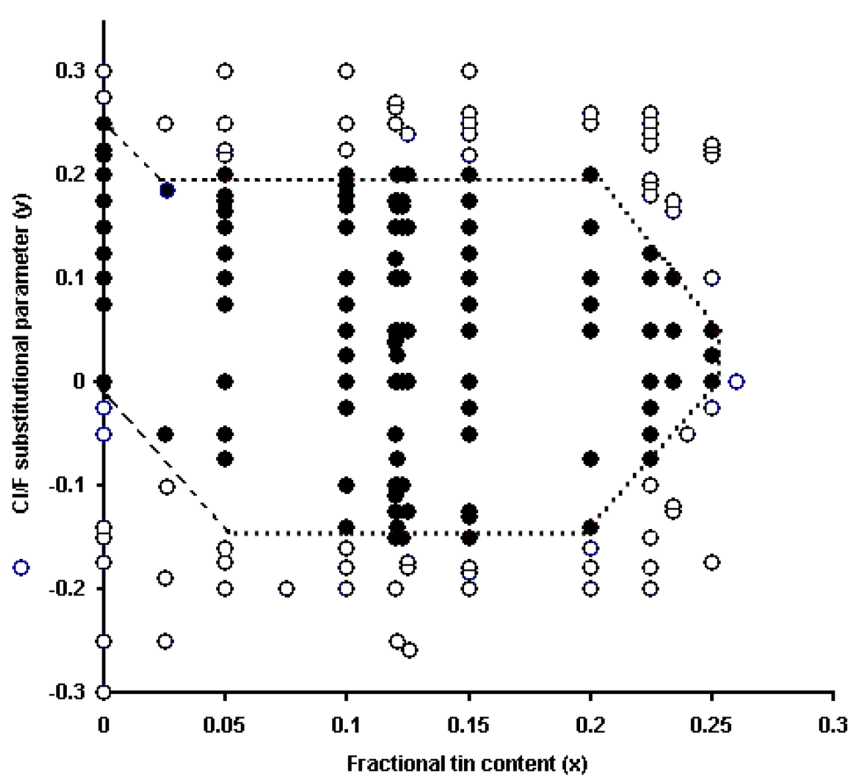

Fig. 24. Diagram of the $\mathrm{Ba}_{1-x} \mathrm{Sn}_{x} \mathrm{Cl}_{1+y} \mathrm{~F}_{1-y}$ solid solution in the $(x, y)$ plane, obtained by reaction at $350^{\circ} \mathrm{C}$ for $43 \mathrm{~h}$ : • pure $\mathrm{Ba}_{1-x} \mathrm{Sn}_{x} \mathrm{Cl}_{1+y} \mathrm{~F}_{1-y}$ phase, o a mixture of $\mathrm{Ba}_{1-x} \mathrm{Sn}_{x} \mathrm{Cl}_{1+y} \mathrm{~F}_{1-y}$ with other phases.

tion than the tetragonal system of $\mathrm{BaClF}$ (since there is no peak splitting) and no order between $\mathrm{Sn}$ and $\mathrm{Ba}$, or between the extra $\mathrm{F}$ for $y<0$ or between the extra $\mathrm{Cl}$ for $y>0$ with the other $\mathrm{F}$ and $\mathrm{Cl}$, other than the ... F $\mathrm{Cl} \mathrm{F} \mathrm{Cl} \mathrm{...} \mathrm{order} \mathrm{of} \mathrm{sheets} \mathrm{perpendicular} \mathrm{to} \mathrm{the} c$ axis present in $\mathrm{BaCl}$ (Fig. 1a) (since there are no superstructure peaks).

(b) Mössbauer spectroscopy shows that, when there is an excess of $\mathrm{Cl}(y>0 \Rightarrow C l / F>1)$, bonding at tin(II) is ionic (a single line at ca. $4 \mathrm{~mm} / \mathrm{s}$ ) and extremely weak (very weak, barely detectable, spectrum at ambient temperature) (Fig. 25b). Weak ionic bonding was found to be present at all $y$ values for low $x$ values (at low tin content). Figure 26a shows how a $\mathrm{Sn}^{2+}$ stannous ion would

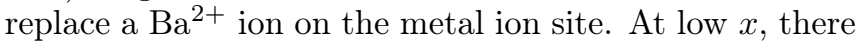
is much more $\mathrm{Ba}^{2+}$ than $\mathrm{Sn}^{2+}$, therefore the size of the lattice is determined mostly by the size of the $\mathrm{Ba}^{2+}, \mathrm{Cl}^{-}$ and $\mathrm{F}^{-}$ions, and since $\mathrm{Ba}^{2+}$ is much larger than $\mathrm{Sn}^{2+}$, tin rattles in the oversized site, hence the very low recoilfree fraction of ionic tin that gives a very weak Mössbauer spectrum at ambient temperature (Fig. 25b) and the thermal motion is frozen at cryogenic temperatures (Fig. 25c). Replacing some $\mathrm{F}^{-}$by bulkier $\mathrm{Cl}^{-}$increases the size of the metal ion site, and it also increases the chance of ionic bonding [8]. The presence of $\mathrm{Sn}^{2+}$ ions agrees with the Hume-Rothery rule about the same type of bonding, however it violates very grossly the rule of similar ionic sizes and it results that $\mathrm{Sn}^{2+}$ is too small to form significant bonding to the surrounding fluoride and chloride ions, hence the rattling. The large width of the line shows that there is an unresolved quadrupole splitting. This is expected since the site is neither cubic, nor octahedral nor tetrahedral.
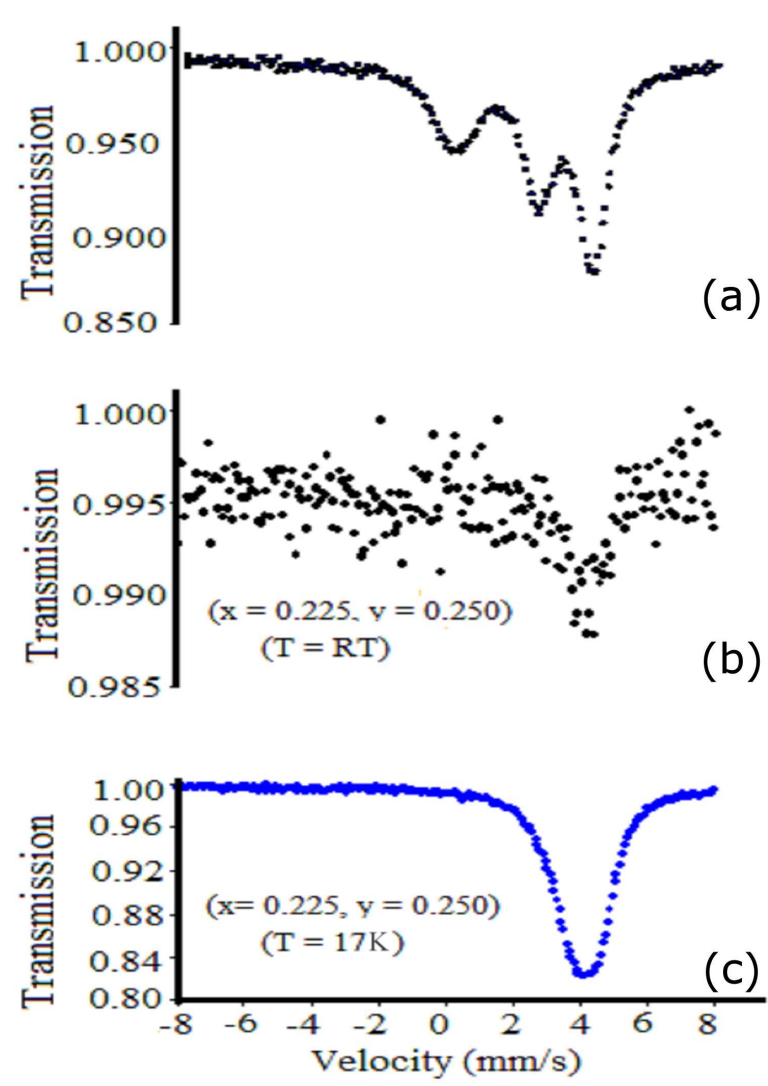

Fig. 25. ${ }^{119} \mathrm{Sn} \quad$ Mössbauer spectrum of $\mathrm{Ba}_{1-x} \mathrm{Sn}_{x} \mathrm{Cl}_{1+y} \mathrm{~F}_{1-y}$ solid solution prepared by solid state reaction at $350{ }^{\circ} \mathrm{C}$ for $43 \mathrm{~h}, x=0.225$ with (b) $y=0.25$ at $298 \mathrm{~K}$, (c) $y=0.25$ at $17 \mathrm{~K}$, and (a) $y=-0.15$ at $298 \mathrm{~K}$. Spectra (b) and (c) were measured on the same sample, hence containing the same amount of tin, using the same $\gamma$-ray source and the same setup. Only the temperature was changed. It took 21 days to get spectrum (b) and only 2 days to get spectrum (c).

(c) At negative $y$ values $(\mathrm{F} / \mathrm{Cl}>1)$, there is more chance of forming covalent bonding like in $\mathrm{SnF}_{2}$ (Fig. 2), in $\mathrm{MSnF}_{4}$ (Fig. 1c) and in $\mathrm{M}_{1-x} \mathrm{Sn}_{x} \mathrm{~F}_{2}$ (Fig. 21), and in addition, at large $x$ values, there is a significant chance of a few tin atoms being neighbors and forming $-\mathrm{F}-\mathrm{Sn}-\mathrm{F}-$ $\mathrm{Sn}-\mathrm{F}$ - oligomers since polymerization is quite common when tin binds to fluorine (Fig. 2). This gives rise to the model of Fig. 26b. The strength of the Sn-F bonds and the room taken by the stereoactive lone pair provides enough stability to prevent excess thermal vibrations and keep the recoil-free fraction at a value similar to that of $\mathrm{SnF}_{2}$, hence a spectrum strong enough to be easily detected at ambient temperature. The doublet of Fig. 25a shows the presence of covalent bonding like the one proposed in the model of Fig. 26b. However, the asymmetry of the spectrum increases rapidly when $y$ increases, to give a single line characteristic of ionic tin. This can be explained only by the overlap of a quadrupole doublet and a single line, with the high velocity line of the doublet and the single line overlapping nearly perfectly. This shows that the $\mathrm{Ba}_{1-x} \mathrm{Sn}_{x} \mathrm{Cl}_{1+y} \mathrm{~F}_{1-y}$ solid solution 
contains either only $\mathrm{Sn}^{2+}$ (low $x$ and high $y$ ) or a mixture of covalently bonded tin(II) and $\mathrm{Sn}^{2+}$, (high $x$ and low $y$ ) however all the tin is never present with covalent bonding. The presence of covalently bonded tin(II) violates the Hume-Rothery rule about the same bonding type, and the similar size rule is also grossly violated. The stereoactive lone pair compensates, at least in part, for the size difference.

(a)

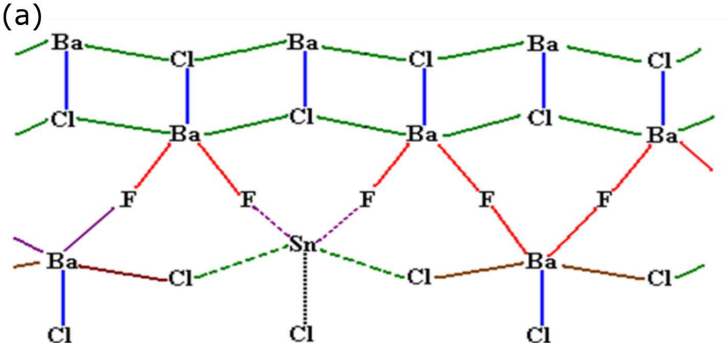

(b)

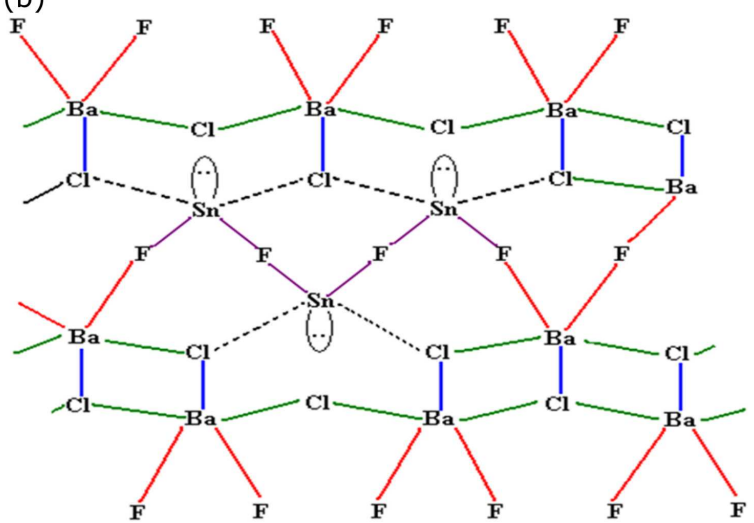

Fig. 26. Tin(II) bonding in $\mathrm{Ba}_{1-x} \mathrm{Sn}_{x} \mathrm{Cl}_{1+y} \mathrm{~F}_{1-y}$ : (a) ionic bonding in a solid solution dilute in tin ( $x$ low) and rich in $\mathrm{Cl}(y>0)$, (b) clusters of covalently bonded tin in systems richer in tin ( $x$ high) and rich in $\mathrm{F}(y<0)$. The dashed lines show weak interactions.

\section{Conclusion}

The present study has provided some major results concerning the materials containing divalent tin and that have a structure closely related to the fluorite-type structure.

(a) It has shown that an appropriate combination of Xray powder diffraction and the Mössbauer spectroscopy results can be very helpful in understanding how tin(II) fits in the typically ionic fluorite structure.

(b) In the case of $\alpha-\mathrm{PbSnF}_{4}$, the very extreme case of preferred orientation made it possible to determine the orientation of the stereoactive lone pair from the variation of the asymmetry of the Mössbauer quadrupole doublet with the orientation of the sample in the $\gamma$-ray beam, in relation with the orientation of the unit-cell axes.

(c) In the case of disordered structures, fluorides or chloride fluorides, stoichiometric or non-stoichiometric, stable structures and metastable $\mathrm{PbSn}_{4} \mathrm{~F}_{10}$ were formed despite blatant violations of the Hume-Rothery rules. (d) The disordered fluorides contain covalently bonded tin(II) in the square pyramidal coordination and with the square pyramidal electron pair geometry, unfavored by the VSEPR model, hence stabilized by the lattice energy.

(e) The case of $\mathrm{PbSn}_{4} \mathrm{~F}_{10}$ is highly unusual: despite the random replacement of $80 \%$ of the $\mathrm{Pb}^{2+}$ in cubic coordination by covalently bonded tin forming softer bonding only on one side of each tin atom, the stereoactive lone pair being on the other side exerting repulsions on bonding pairs, the compound is stable for a time sufficiently long to be studied (from a few hours to a few days). It is the same as removing $80 \%$ of the bricks from all over a wall, at random, and the wall still stands up.

(f) The case of the $\mathrm{Ba}_{1-x} \mathrm{Sn}_{x} \mathrm{Cl}_{1+y} \mathrm{~F}_{1-y}$ solid solution is the most complex by far. It is doubly nonstoichiometric, for metals $(\mathrm{Sn} / \mathrm{Ba})$ and for the halogens $(\mathrm{Cl} / \mathrm{F})$. It contains tin(II) being either all ionic or a mixture of covalently bonded $\operatorname{tin}(\mathrm{II})$ and $\mathrm{Sn}^{2+}$, depending on the amount of tin $(x)$ and on the relative amounts of $\mathrm{Cl}$ and $\mathrm{F}(y)$. This solid solution is the first example of the presence of covalently bonded $\operatorname{tin}(\mathrm{II})$ and ionic $\mathrm{Sn}^{2+}$ in the same compound, and moreover disordered with one another on the same site, and furthermore both are disordered with the much larger $\mathrm{Ba}^{2+}$ ions.

(g) Usually, the recoil-free fraction is a function of the overall lattice strength. In the case of $\mathrm{Ba}_{1-x} \mathrm{Sn}_{x} \mathrm{Cl}_{1+y} \mathrm{~F}_{1-y}$ with only $\mathrm{Sn}^{2+}$, in particular for $\mathrm{Cl} / \mathrm{F}>1$, only the $\mathrm{Sn}^{2+}$ site is very soft within an overall hard crystal lattice, hence a very low recoil-free fraction for $\mathrm{Sn}^{2+}$ despite a strong crystal lattice.

\section{Acknowledgments}

This report is dedicated to the memory of Professor Krzysztof Ruebenbauer who has been a guiding light throughout my Mössbauer spectroscopy career. The French Centre National de la Recherche Scientifique (CNRS), the Canadian Natural Science and Engineering Research Council (NSERC), Concordia University and The Procter and Gamble Co., Cincinnati, Ohio, USA, are gratefully acknowledged for supporting parts of this work.

\section{References}

[1] R.D. Shannon, C.T. Prewitt, Acta Crystallogr. B 25, 925 (1969).

[2] E.D. Brackett, T.E. Brackett, R.L. Sass, J. Phys. Chem. 67, 2132 (1963).

[3] R.C. McDonald, H. Ho-Kuen Hau, K. Eriks, Inorg. Chem. 15, 762 (1976).

[4] G. Dénès, J. Pannetier, J. Lucas, J.Y. Le Marouille, J. Solid State Chem. 30, 335 (1979).

[5] G. Dénès, J. Pannetier, J. Lucas, J. Solid State Chem. 33, 1 (1980).

[6] J. Pannetier, G. Dénès, M. Durand, J.L. Buevoz, J. Phys. (France) 41, 1019 (1980).

[7] B. Kamenar, D. Grdenič, J. Chem. Soc. 1961, 3954 (1961). 
[8] G. Dénès, A. Muntasar, S. Boufas, H. Merazig, Hyperfine Interact. 166, 345 (2005).

[9] C. Geneys, S. Vilminot, L. Cot, Acta Crystallogr. B32, 3199 (1976).

[10] G. Bergerhoff, L. Goost, Acta Crystallogr. B30, 1362 (1974).

[11] G. Dénès, Mater. Res. Bull. 15, 807 (1980).

[12] CRC Handbook of Chemistry and Physics, Eds. R.C. Weast, M.J. Astle, 61st ed., CRC Press, Boca Raton 1980-1981, p. B-73.

[13] G. Dénès, J. Solid State Chem. 77, 54 (1988).

[14] K. Ruebenbauer, Ł. Duraj, MOSGRAF-2009.

[15] G. Dénès, Mater. Res. Soc. Symp. Proc. 369, 295 (1995).

[16] K. Fajans, Naturwissenchaften 11, 165 (1923).

[17] K. Fajans, G. Joos Z. Phys. 23, 1 (1924).

[18] K. Fajans, Z. Kristallogr. 61, 18 (1924).

[19] D. Ansel, J. Debuigne, G. Dénès, J. Pannetier, J. Lucas, Ber. Bunsenges. Phys. Chem. 82, 376 (1978).

[20] J. Galy, G. Meunier, S. Andersson, A. Aström, J. Solid State Chem. 13, 142 (1975).
[21] R.J. Gillespie, R.S. Nyholm, Quart. Rev. Chem. Soc. 11, 339 (1957).

[22] R.W.G. Wyckoff, Cryst. Struct. Intersci., Vol. I, New York 1965, p. 134.

[23] J. Pannetier, G. Dénès, Acta Crystallogr. B36, 2763 (1980).

[24] I.D. Brown, J. Solid State Chem. 11, 214 (1974).

[25] G. Dénès, M.C. Madamba, Mater. Struct. 3, 227 (1996).

[26] N.N. Greenwood, T.C. Gibb, Mössbauer Spectroscopy, Chapman and Hall, London 1971, p. 66.

[27] T. Birchall, G. Dénès, K. Ruebenbauer, J. Pannetier, Hyperfine Interact. 29, 1331 (1986).

[28] B.D. Cullity, Elements of X-ray Diffraction, 2nd ed., Addison-Wesley, Don Mills, Ontario 1978, p. 192, 284.

[29] W. Hume-Rothery, H.M. Powell, Z. Kristallogr. 91, 23 (1935).

[30] G. Dénès, A. Muntasar, Hyperfine Interact. 153, 121 (2004).

[31] J.D. Donaldson, B.J. Senior, J. Chem. Soc. A 1967, 1821 (1967) 